\title{
Maternal stress programs a demasculinization of glutamatergic transmission in stress-related brain regions of aged rats
}

\author{
Remy Verhaeghe • Vance Gao • \\ Sara Morley-Fletcher • Hammou Bouwalerh • \\ Gilles Van Camp • Francesca Cisani • \\ Ferdinando Nicoletti $\cdot$ Stefania Maccari $(\mathbb{D}$
}

Received: 16 August 2020 / Accepted: 20 April 2021 / Published online: 13 May 2021

(C) The Author(s) 2021

\begin{abstract}
Brain aging may be programmed by earlylife stress. Aging affects males and females differently, but how perinatal stress (PRS) affects brain aging between sexes is unknown. We showed behavioral and neurobiological sex differences in non-stressed control rats that were strongly reduced or inverted in PRS rats. In particular, PRS decreased risk-taking behavior, spatial memory, exploratory behavior, and fine motor behavior in male aged rats. In contrast, female aged PRS rats displayed only increased risk-taking behavior and reduced exploratory behavior. PRS induced large reductions in the expression of glutamate receptors in the
\end{abstract}

Ferdinando Nicoletti and Stefania Maccari contributed equally to this work and are co-directors of the LIA international laboratory.

R. Verhaeghe $\cdot$ F. Nicoletti

IRCCS Neuromed, (IS), Pozzilli, Italy

V. Gao $\cdot$ S. Morley-Fletcher $\cdot$ H. Bouwalerh $\cdot$

G. Van Camp · F. Cisani · S. Maccari $(\bowtie)$

Unité de Glycobiologie Structurale et Fonctionnelle, University of Lille, CNRS, UMR 8576, UGSF, F-59000 Lille, France

e-mail: stefania.maccari@univ-lille.fr

S. Morley-Fletcher $\cdot$ H. Bouwalerh · G. Van Camp International Associated Laboratory (LIA) "Perinatal Stress and Neurodegenerative Diseases", University of Lille - CNRS, UMR 8576, Lille, France

S. Morley-Fletcher · H. Bouwalerh · G. Van Camp International Associated Laboratory (LIA) "Perinatal Stress and Neurodegenerative Diseases", Sapienza University of Rome - ventral and dorsal hippocampus and prefrontal cortex only in male rats. PRS also reduced the expression of synaptic vesicle-associated proteins, glucocorticoid receptors (GR), and mineralocorticoid receptors (MR) in the ventral hippocampus of aged male rats. In contrast, in female aged rats, PRS enhanced the expression of MRs and brain-derived neurotrophic factor (BDNF) in the ventral hippocampus and the expression of glial fibrillary acidic protein (GFAP) and BDNF in the prefrontal cortex. A common PRS effect in both sexes was a reduction in exploratory behavior and metabotropic glutamate $(\mathrm{mGlu} 2 / 3)$ receptors in the ventral

IRCCS Neuromed, Rome, Italy

F. Cisani

Department of Pharmacy (DiFar), University of Genoa, Viale Cembrano 4, 16148 Genoa, Italy

\section{F. Nicoletti}

Department of Physiology and Pharmacology "V. Erspamer", Sapienza University of Rome, Rome, Italy

\section{S. Maccari}

Department of Science and Medical-Surgical Biotechnology, Sapienza University of Rome, Rome, Italy 
hippocampus and prefrontal cortex. A multidimensional analysis revealed that PRS induced a demasculinization profile in glutamate-related proteins in the ventral and dorsal hippocampus and prefrontal cortex, as well as a demasculinization profile of stress markers only in the dorsal hippocampus. In contrast, defeminization was observed only in the ventral hippocampus. Measurements of testosterone and $17-\beta$-estradiol in the plasma and aromatase in the dorsal hippocampus were consistent with a demasculinizing action of PRS. These findings confirm that the brains of males and females differentially respond to PRS and aging suggesting that females might be more protected against early stress and age-related inflammation and neurodegeneration. Taken together, these results may contribute to understanding how early environmental factors shape vulnerability to brain aging in both sexes and may lay the groundwork for future studies aimed at identifying new treatment strategies to improve the quality of life of older individuals, which is of particular interest given that there is a high growth of aging in populations around the world.

Keywords Early life stress $\cdot$ Sex differences $\cdot$ Brain aging $\cdot$ Behaviors $\cdot$ Hormones

$\begin{array}{ll}\begin{array}{l}\text { Abbreviations } \\ \text { AMPA }\end{array} & \begin{array}{l}\alpha \text {-Amino-3-hydroxy-5- } \\ \text { méthylisoazol-4-propionate acid }\end{array} \\ \text { BDNF } & \text { Brain-derived neurotrophic factor } \\ \text { C } & \text { Control } \\ \text { CNS } & \text { Central nervous system } \\ \text { CONT } & \text { Control } \\ \text { COVID-19 } & \text { Coronavirus disease 2019 } \\ \text { DOHaD } & \text { Developmental Origins of Health } \\ & \text { and Disease } \\ \text { E }_{2} & \text { Estradiol } \\ \text { EPM } & \text { Elevated plus maze } \\ \text { F } & \text { Female } \\ \text { GFAP } & \text { Glial fibrillary acidic protein } \\ \text { GR } & \text { Glucocorticoid receptor } \\ \text { HPA } & \text { Hypothalamic-pituitary-adrenal } \\ & \text { axis } \\ \text { IL-6 } & \text { Interleukin-6 } \\ \text { ITI } & \text { Intertrial interval } \\ \text { M } & \text { Male } \\ \text { mGlu } & \text { Metabotropic glutamate receptor } \\ \text { MR } & \text { Mineralocorticoid receptor } \\ \text { NMDA } & \text { N-Methyl-D-aspartate } \\ \text { OXTR } & \text { Oxytocin receptor } \\ & \end{array}$

$\begin{array}{ll}\text { P } & \text { Perinatal stress } \\ \text { PC } & \text { Principal component } \\ \text { PCA } & \text { Principal component analysis } \\ \text { PERMANOVA } & \text { Permutational MANOVA } \\ \text { PRS } & \text { Perinatal stress } \\ \text { PSD95 } & \text { Postsynaptic density protein 95 } \\ \text { SNAP-25 } & \text { Synaptosomal-associated protein, 25 } \\ & \text { kDa } \\ \text { SYP } & \text { Synaptophysin } \\ \text { VAMP } & \text { Vesicle-associated membrane } \\ & \text { proteins } \\ \text { vGLUT1 } & \text { Vesicular glutamate transporter 1 } \\ \text { VGLUT2 } & \text { Vesicular glutamate transporter 2 } \\ \text { xCT } & \text { Cystine/glutamate antiporter }\end{array}$

\section{Introduction}

Aging is characterized by a progressive loss of physiological integrity, leading to impaired function and increased risk of death ([1]). Aging affects males and females differently [2-4]. This is extremely important if we consider, for example, the current global coronavirus disease 2019 (COVID-19) pandemic, where aging is known to be a key risk factor for severe COVID-19 [5]. Males have been found to be more vulnerable to COVID-19 than females [6]. Furthermore, stress is wellknown to contribute to the variability of the aging process and the development of age-related central nervous system (CNS) disorders [7-9]. The stress hormones, glucocorticoids, regulate a cohort of physiological functions, such as intermediary metabolism and the immune system, and influence development, growth, and aging [10]. Excess of glucocorticoids, as occurs during chronic stress, may alter physiological aging [11-13]. Studies in animals and humans have shown that stressful events during critical periods of brain development cause lifelong alterations in brain programming [14, 15]. Earlylife stress impacts cognitive processing during aging, as demonstrated in middle-aged and aged male rodents performing the Y-maze test and touch panel operant task [16, 17]. Perinatal stress (PRS) affects other aging-related processes in adult male rats, as indicated by an increased expression of pro-inflammatory markers [18], inhibition of neurogenesis in the hippocampus [19], and accelerated aging of the hypothalamic-pituitary-adrenal (HPA) axis [16, 20]. Glutamate, the most abundant excitatory neurotransmitter in the CNS, 
is deeply involved in stress-related disorders [21, 22]. Glutamatergic pyramidal neurons that mediate corticocortical connections between the association cortices and excitatory hippocampal connections are particularly vulnerable to aging $[23,24]$. Importantly, glutamate plays a key role in the programming effects induced by PRS. Indeed, PRS greatly reduces glutamate release in the ventral hippocampus of adult male rats, an effect associated with reduced expression of synaptic vesicleassociated proteins [25-27]. Enhancing glutamate release through a cocktail of metabotropic glutamate receptor (mGlu) $2 / 3$ and $\mathrm{GABA}_{\mathrm{B}}$ receptor antagonists reverses the alterations in risk-taking behavior in PRS rats [26], reinforcing the idea that impairment of the glutamatergic synapse in the ventral hippocampus lies at the core of the pathological phenotype triggered by PRS.

The decline in gonadal hormones that occurs with aging is associated with stress deregulation in males and females [8, 28]. Furthermore, gonadal hormones are altered by PRS, as demonstrated by increased plasma dihydrotestosterone levels in adult male PRS rats and lower plasma estradiol $\left(\mathrm{E}_{2}\right)$ levels in adult PRS females [29]. Interestingly, a decrease in estradiol levels was still observed in middle-aged female rats, suggesting that PRS accelerates the agingrelated-disruption of the estrous cycle [30, 31]. These hormonal changes are associated with sex differences in the behavior of adult PRS rats. For example, PRS decreases risk-taking behavior (measured in the elevated plus maze) in males but not in females [32] and differentially affects addictive behavior in males and females [29]. Other studies using prenatal stress paradigms have shown disruptions of sex differences in behavior, morphology, sex hormones, and gene expression profiles [33-37]. This suggests that the early perinatal period represents a specific window of sensitivity during which offspring are susceptible to the programming effects of PRS combined with sex differences. Interestingly, specific patterns of demasculinization have already been reported in fetal and adult life at physiological and behavioral levels [37-43]. However, very little is known about the brain-gonadal axis. For example, a possible link between plasma testosterone levels and glial fibrillary acidic protein (GFAP) expression in the CNS has been shown. In particular, previous studies have shown an inverse correlation between plasma testosterone levels and the age-dependent increase in GFAP messenger ribonucleic acid (mRNA) levels in the rat and human brain [44]. In addition, testosterone replacement lowered GFAP levels in the cerebellum of castrated male aged rats [45]. However, most studies concerning stressful perinatal events have been carried out in adult males. To our knowledge, there are no studies on the effects of PRS in elderly male and female rats and the effect on the brain-gonadal axis. Thus, we investigated the long-lasting programming effects of PRS in both sexes on behaviors and biochemical markers of glutamatergic transmission, stress, neuroplasticity, and sex hormones. To this aim, we used the PRS rat model, in which exposure of pregnant mothers to restraint stress reduces maternal behavior, to study neuroplasticity in brain regions sensitive to stress (ventral and dorsal hippocampus, prefrontal cortex and striatum), and cognitive and motor behaviors in male and female rats aged 21-22 months.

\section{Materials and methods}

\section{Experimental design}

The experimental timeline is shown in Fig. 1. After the PRS procedure, which consisted of restraint stress of pregnant mothers and the reduction of maternal behavior in the first postpartum week, behavioral and biochemical measurements in the hippocampus (ventral and dorsal), prefrontal cortex, and striatum in both male and female rats (21-22 months) were studied. Behavioral tests were performed when the rats were 21 months old. One week after the last behavioral test, the brain structures and blood (plasma and serum) were collected. All experiments followed the rules of the European Communities Council Directive 86/609/EEC. The Local Committee CEEA-75 (Comité d'Ethique en Experimentation Animale Nord-Pas-de-Calais, 75) approved the experimental procedures.

\section{Animals}

Thirty nulliparous female Sprague Dawley rats, weighing approximately $250 \mathrm{~g}$, were purchased from Charles River (France) and housed under standard conditions with a 12-h light/dark cycle. After group housing (five females/cage) for 2 weeks, each female was individually housed for 1 week with a sexually experienced 


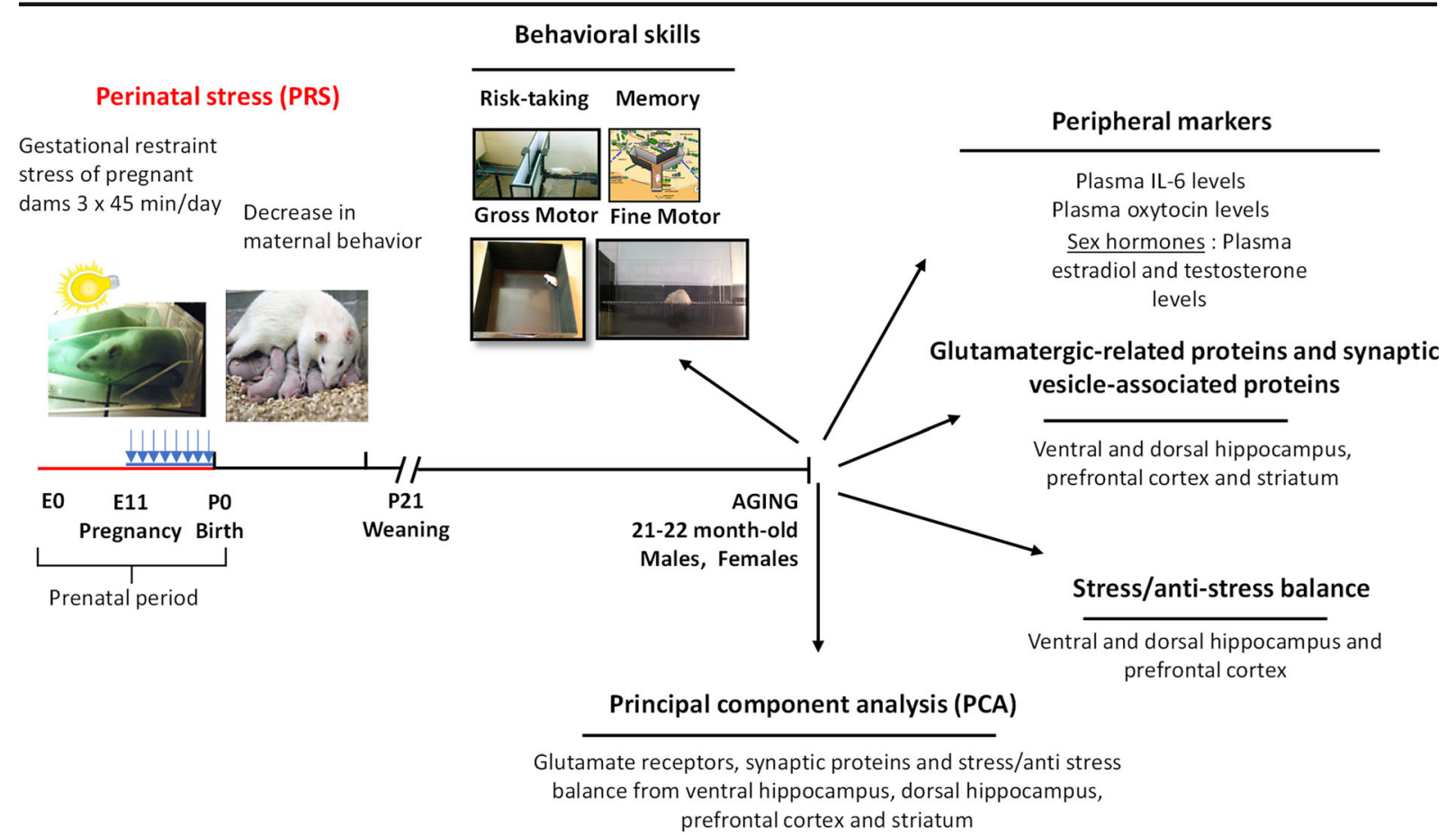

Fig. 1 Experimental design and timeline. Induction of PRS and maternal behavior analysis in the first postpartum week were followed by behavioral and biochemical measurements in the
21-22 month old male and female progeny as indicated. Several multidimensional analyses have been performed

for the experiments. Animals were housed in groups of two or three and maintained under similar environmental conditions during their entire life span; 21-22-month old rats were used in all experiments. The animals were weighed at 21 months prior to the behavioral assessment.

\section{Maternal behavior}

Maternal behavior was monitored for $24 \mathrm{~h}$ every day during the first 7 postpartum days. Constant monitoring was performed with small infrared cameras placed on the animal cage rack where cages containing lactating females were placed. Within each observation period, the behavior of each mother was scored every minute from postpartum day 1 to day 7 (60 observations/h with $2 \mathrm{~h}$ of observation per day, $1 \mathrm{~h}$ before lights off, and $1 \mathrm{~h}$ after lights on). The active behavior of the mother (nursing behavior, grooming, licking, and carrying pups) was scored, and the data obtained were expressed as percentages with respect to the total number of observations. Because gestational stress induces a reduction of maternal behavior [46], we refer to the whole procedure as perinatal stress (PRS). 
Behavioral studies

\section{Risk-taking behavior in an elevated plus maze test and exploratory behavior}

Risk-taking behavior of PRS or control progeny [27] was assessed in the elevated plus maze test (EPM) [47]. Briefly, the test was performed for 5 min early in the afternoon (between 1 and $4 \mathrm{pm}$ ) and began with the placement of the rat in the center of the maze with the head facing a closed arm. We used a custom-made EPM apparatus described by Vallée et al. [16], with closed and open arms of $20 \times 20 \mathrm{~cm}$. The closed arms' luminosity was approximately $25 \mathrm{~lx}$, and the luminosity of the open arms was approximately $50 \mathrm{~lx}$. Behavior was recorded by a video camera and manually scored by a trained observer blind to the animals' condition (PRS and control) using a software package (Noldus, The Observer $($ ). The time spent in the open and closed arms was measured, and the percentage of time spent in the open arms was calculated and analyzed as risk-taking behavior. The number of closed arms entries was analyzed as exploratory behavior.

\section{Fine motor skills in the ladder rung-walking test}

The horizontal ladder rung-walking test apparatus [48] consisted of side walls made of clear plexiglass and metal rungs ( $3 \mathrm{~mm}$ diameter), which could be inserted to create a floor with a minimum distance of $1 \mathrm{~cm}$ between rungs. The sidewalls were $1 \mathrm{~m}$ long and $19 \mathrm{~cm}$ high, as measured from the height of the rungs. The ladder was elevated $30 \mathrm{~cm}$ above the ground with a refuge (home cage) at the end. Varying the position of the metal rungs modified the difficulty of the task. A regular pattern of the rungs allowed the animals to learn the pattern over several training sessions and to anticipate the position of the rungs. To increase the test's difficulty, after the training sessions, an irregular pattern was created to analyze how rats managed to cross the ladder. The test was recorded using two video cameras. One video camera was placed in front of the first half of the ladder at a slight ventral angle, and the other was placed in front of the second half of the ladder at a slight ventral angle to precisely analyze the misplacement of the rat paw. Following the video recording, the foot faults were scored. A score of one was assigned when the rat's paw was misplaced, and a score of two was assigned when the rat's paw severely slipped or missed.
Then, the percentage increase in errors between the last training and the test with the irregular pattern was calculated as follows: error score irregular pattern - error score last training/error score last training $* 100$.

\section{Spatial recognition memory in Y-maze and exploratory} behavior

Spatial recognition memory was measured in a two-trial memory task in a Y-maze [16] made of gray plastic with three identical arms $(50 \mathrm{~cm})$ enclosed with $32-\mathrm{cm}$-high side walls and illuminated by dim light (40 lx). Each arm was equipped with two infrared beams, one at each end of the arm. The maze floor was covered with rat odor-saturated sawdust, and the sawdust was mixed between each session to eliminate olfactory cues. Visual cues were placed in the testing room and kept constant during the behavioral testing sessions. The task consisted of two trials separated by a time interval. In the first trial (acquisition phase), one arm of the Y-maze was closed, and animals could visit the two other arms for $5 \mathrm{~min}$. During the intertrial interval (ITI), rats were housed in their home cages, which were different from the test room. During the second trial (retention phase), animals had free access to the three arms and were again allowed to explore the maze for $5 \mathrm{~min}$. The time spent in the novel arm (previously closed in the first trial) was calculated as a percentage of the total time spent in all three arms during the first $3 \mathrm{~min}$ of the second trial. This time corresponds to the maximal exploratory activity in the novel arm, which subsequently declines [49]. Time spent in the novel arm above chance (i.e., 33\%) indicates spatial recognition. Memory performance was tested with an ITI of $6 \mathrm{~h}$. Total entries in the different arms were analyzed for $5 \mathrm{~min}$ as a measure of the exploration behavior.

\section{Gross motor skills-locomotor activity in the open-field arena}

Exploratory behavior was evaluated by placing a rat into a corner of an open-field arena $(100 \times 100 \times 50 \mathrm{~cm})$, allowing the rat to explore the field for $10 \mathrm{~min}$ freely. Lightning was approximately $60 \mathrm{~lx}$ inside the arena. Activity and trajectory length in the open-field was recorded and quantified by Video Track® (Viewpoint, Lyon, France). 
Western blot analysis

The hippocampus (ventral and dorsal), striatum, and prefrontal cortex of control (CONT) and PRS male and female rats were rapidly dissected and immediately stored at $-80^{\circ} \mathrm{C}$. Glutamate-related proteins and synaptic vesicle-associated proteins were assessed in synaptosomes. To isolate synaptosomes, tissue was manually homogenized with a potter in ten volumes of HEPESbuffered sucrose $(0.32 \mathrm{M}$ sucrose, $4 \mathrm{mM}$ HEPES $\mathrm{pH}$ 7.4). All procedures were performed at $4{ }^{\circ} \mathrm{C}$. Homogenates were centrifuged at $1000 \times \mathrm{g}$ for $10 \mathrm{~min}$, and the resulting supernatants were centrifuged at $10,000 \times \mathrm{g}$ for $15 \mathrm{~min}$. The pellet obtained from the second centrifugation was resuspended in ten volumes of HEPESbuffered sucrose [26]. This pellet contained the crude synaptosomal fraction. BCA assay was used to determine protein concentration. Synaptosome lysates were resuspended in Laemmli reducing buffer, and $20 \mu \mathrm{g}$ for synaptosomal fraction or $35 \mu \mathrm{g}$ from the total homogenates of each sample were loaded. The samples were loaded in two different gels. One of the samples was used as an internal control and was loaded in each gel to ensure sample homogeneity between different gels and compare samples from different gels.

Proteins were first separated by electrophoresis on sodium dodecyl sulfate-polyacrylamide gels according to their molecular weight and then transferred to nitrocellulose membranes (Bio-Rad). The transfer was performed at $4{ }^{\circ} \mathrm{C}$ in a buffer containing $35 \mathrm{mM}$ Tris, $192 \mathrm{mM}$ glycine, and $20 \%$ methanol. After transfer, blots were incubated in a blocking solution containing Tris-buffered saline and $5 \%(\mathrm{w} / \mathrm{v})$ non-fat milk. All the following antibodies were first tested with control samples to determine the optimal conditions for use. To analyze several proteins per membrane, membranes were cut according to the molecular weight of the protein of interest. We used the following primary antibodies on synaptosomal fraction: mouse polyclonal antisynaptosomal-associated protein, $25 \mathrm{kDa}$ (SNAP25), rabbit polyclonal anti-synapsin Ia/b (1:4000; catalog \#sc-20780), rabbit polyclonal anti-synaptophysin (1:8000; catalog \#sc-9116), rabbit polyclonal antisyntaxin (1:4000, catalog \#sc-13994), and rabbit polyclonal anti-synapsin IIa (1:4000; catalog \#sc25538), all purchased from Santa Cruz Biotechnology; mouse monoclonal anti-rab3a (1:2000; catalog \#107111), mouse monoclonal anti-Munc-18
(1:2000; catalog \#116011), and mouse polyclonal anti-vesicle-associated membrane proteins (VAMP) (1:1500; catalog \#104 111) which were purchased from Synaptic Systems; rabbit polyclonal antimGlu5 receptors $(1: 1000$; catalog \#AB5675) and rabbit polyclonal anti-mGlu2/3 receptors $(1: 1000$; catalog \#06-676), all purchased from Millipore; rabbit polyclonal anti-GluN1 (1:2000; catalog \#ab109182); rabbit monoclonal anti-GluA2 (1/2000; catalog \#ab206293), rabbit polyclonal anti-GluN2A (1:500; catalog \#ab14596), mouse monoclonal anti-GluN2B (1/1000; catalog \#ab28373), rabbit monoclonal anti-VGLUT1 (1/1000; catalog \#ab180188), and rabbit polyclonal anti-vesicular glutamate transporter 2 (VGLUT2) (1/1000; catalog \#ab84103) purchased from Abcam; mouse monoclonal anti-GluA3 (1/800; catalog \#MAB5416) purchased from Merck; and rabbit polyclonal anti-cystine/glutamate antiporter (xCT) (1/500; catalog \#KE021) purchased from TransGenic Inc. We used the following primary antibodies on total homogenates: rabbit polyclonal anti-GR (1/1000; catalog \#24050-1-AP), rabbit polyclonal anti-GFAP (1/1500; catalog \#16825-1-AP), and rabbit polyclonal anti-BDNF (1/1000; catalog \#282051-AP), all purchased from Proteintech; mouse monoclonal anti-aromatase $(1 / 500$; catalog \#sc$7305)$ and rabbit polyclonal anti-oxytocin receptor (OXTR) (1/500; catalog \#sc-33209) purchased from Santa Cruz; and rabbit polyclonal anti-MR (1/1000; catalog \#ab64457) from Abcam. To ensure that each lane was loaded with an equivalent amount of proteins, the blots were probed with a mouse monoclonal anti- $\beta$-actin (1:5000; catalog \#A5316, Sigma). All primary antibodies were incubated overnight at 4 ${ }^{\circ} \mathrm{C}$. Horseradish peroxidase-conjugated secondary anti-mouse or anti-rabbit antibodies (purchased from GE-Healthcare) were used at a dilution of 1:7500 and incubated for $1 \mathrm{~h}$ at room temperature. Bands were visualized with an enhanced chemiluminescence system (ECL enhancer Thermo Fisher). After immunoblotting, digitized images of bands immunoreactive for target antibodies and actin were acquired (FUSION ${ }^{\circledR}$ ), and the area of immunoreactivity corresponding to each band was measured using ImageJ. Each blot was normalized to actin. The ratio of target to actin was then determined, and these values were compared for statistical significance. 
Measurement of the interleukin-6 (IL-6), oxytocin, and sex hormones levels

IL-6 ( $\mathrm{pg} / \mathrm{mL})$, oxytocin $(\mathrm{pg} / \mathrm{mL})$, testosterone $(\mathrm{ng} / \mathrm{mL})$, and estradiol levels $(\mathrm{pg} / \mathrm{mL})$ were determined in the plasma extracted from blood samples. Plasma was collected using ethylenediaminetetraacetic acid (EDTA) as an anticoagulant and centrifuged for $15 \mathrm{~min}$ at $1000 \times \mathrm{g}$ at $4{ }^{\circ} \mathrm{C}$. Plasma was stored at $-20{ }^{\circ} \mathrm{C}$ until assessment. All enzyme-linked immunosorbent assay (ELISA) kits were used according to the manufacturer's protocol. All standards, blood samples, and controls were analyzed concurrently in duplicate. The optical density of the samples was determined at $450 \mathrm{~nm}$ using a microplate reader (BioTek Instruments, Winooski, USA).

\begin{tabular}{lll}
\hline ELISA kit & Manufacture & Sensibility range \\
\hline IL-6 & CUSABIO (CSB-E04640r) & $0.312-20 \mathrm{pg} / \mathrm{ml}$ \\
Oxytocin & CUSABIO (CSB-E14197r) & $7.5-600 \mathrm{pg} / \mathrm{ml}$ \\
Testosterone & DEMEDITECH (DEV9911 rat) & $0.066-25 \mathrm{ng} / \mathrm{ml}$ \\
Estradiol & DEMEDITECH (DEV9999 rat) & $2.5-1.280 \mathrm{pg} / \mathrm{ml}$ \\
\hline
\end{tabular}

Multidimensional analyses

To see how sex and stress affect protein quantities more generally, we performed a multidimensional analysis on sets of multiple proteins or behaviors. Proteins were categorized as glutamatergic synapse proteins, synaptic vesicle-associated proteins, or stress/anti-stress balancerelated proteins, and analyses were carried out for each protein set in each brain region.

Since protein levels tended to be correlated with each other, we used a principal components analysis (PCA) to summarize the variation in a protein set and for plotting. For the PCA, individuals who were missing more than $50 \%$ of protein measurements were excluded. Missing values were replaced with the mean of the sexby-PRS group. To quantify distances between groups, we used the median of the Manhattan distances between each individual in one group with the centroid of another group. We created a "demasculinization score," which represents the phenomenon in which PRS causes males to become more similar to females in various aspects. The demasculinization score was the distance from control males to control females divided by the distance from PRS males to control females. A score greater than one signifies that PRS males are more similar to control females than control males. To test the significance of demasculinization, a Mann-Whitney-Wilcoxon test was used to determine if the difference between distances was significant.

Partial correlation

To determine significant relationships between the two measures, we calculated the correlation between the two measures after controlling for sex and group (PRS/ CONT) on both measures. Generally, $Y$ is a behavior, and $X$ is a neurophysiological measure, such as protein or hormone levels. Moreover, $\beta_{1} \neq 0$ indicates a significant correlation between $X$ and $Y$.

\section{Statistical analysis}

Behavioral and biochemical data were expressed as the mean \pm standard error of the mean (SEM) and analyzed using a parametric analysis of variance (ANOVA) with group (CONT vs PRS) and sex (male and female) as independent variables. When group $\times$ sex interaction was present, post hoc comparisons were performed using the Fisher test. A $p$-value of $<0.05$ was considered statistically significant. A permutational MANOVA (PERMANOVA) [50] was used to test differences between groups in ensembles of proteins.

\section{Results}

Sex-specific effects of PRS on behavior of aged rats

For the assessment of risk-taking behavior, we used the EPM (Fig. 2a) to measure the latency to enter the open arm and the time spent in the open arm. We observed a sex-dimorphic profile that was inverted by PRS (latency to open arm, group $\times$ sex effect, $F_{(1,35)}=19.184, p=0.0001 ; \%$ time spent in the open arm, $F_{(1,35)}=13.821, p=0.0007 ; n=8-12$ rats/group). Unstressed (control) female rats showed an increased latency to enter the open arm compared to control males (Fisher, $\# p=0.015$ ). In contrast, PRS females showed reduced latency and increased time spent in the open arm compared to both PRS males (\#\#\#p=0.00088) and control females $(* * p=0.0056)$. The opposite was found in males, in which PRS increased the latency $(* * p=0.0025)$ and reduced the time spent $(* p=0.049)$ in the open arm compared to 
a. Risk-taking behavior
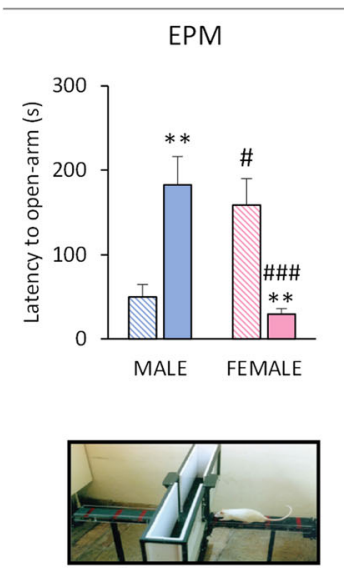

EPM
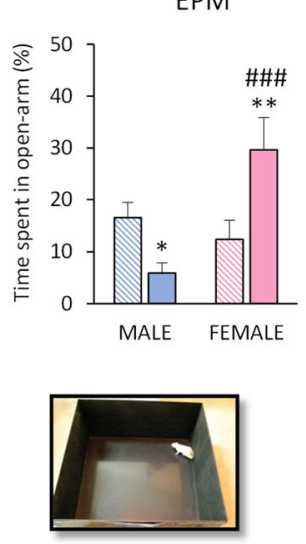

Open field b. Spatial memory

Y-maze
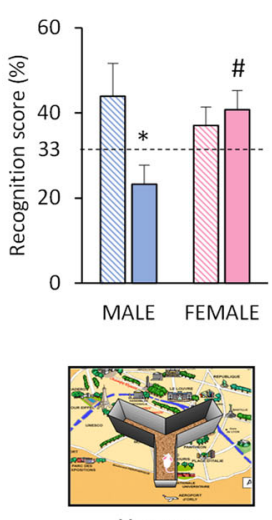

Y-maze

Spatial recognition memory

d. Exploratory behavior

$\mathbb{Q}$ CONT M PRS M

$\mathbb{Q}$ CONT F PRS F

\section{c. Fine motor skills}

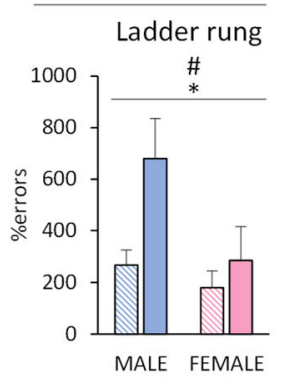

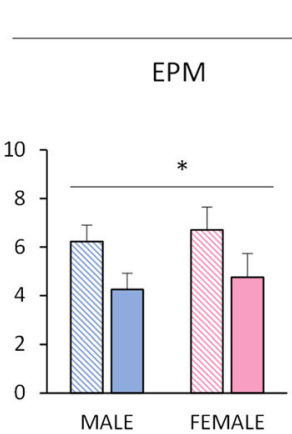
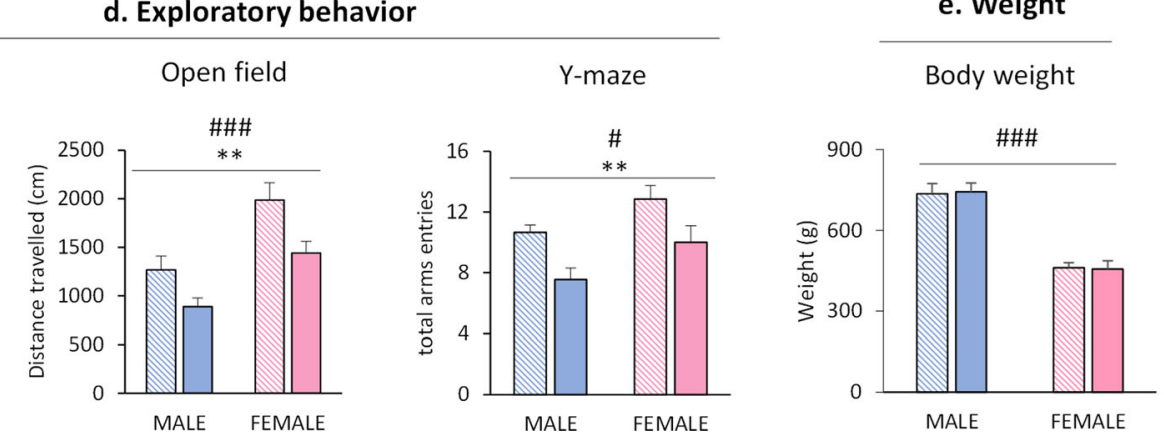

Fig. 2 Sex-specific effects of PRS on behavior of aged rats. Risktaking behavior in the EPM is shown in a. The latency to the open arm and time spent in the open arm were the two parameters analyzed. The spatial recognition memory was studied using the Y-maze. The recognition score (\%) is represented in $\mathbf{b}$. The ladder rung-walking test was used to study the fine motor skills. The percentage of errors is shown in c. Exploratory behavior was

controls. Thus, PRS reduced risk-taking behavior in aged males but caused the opposite effect in females.

The study of spatial recognition memory in the $\mathrm{Y}$ maze test showed a clear sex-dependent effect (group $\times$ sex effect, $F_{(1,29)}=4.641, p=0.04 ; n=8-9$ rats/group). PRS reduced the recognition score in aged male (23.24\% recognition score) (Fisher, $* p=0.014$ ) but not in aged female rats $(40.71 \%)$ as compared to control rats $(43.93 \%$ and $37.04 \%$ in control males and females, respectively). There was a significant difference between PRS male and PRS female rats (Fischer, $\# p=0.040$ ) (Fig. 2b).

To examine fine motor skills, we used the ladder rung-walking test (Fig. 2c). PRS increased the percentage of errors in both sexes (group effect, $F_{(1,35)}=5.235$,

analyzed in the EPM test considering the closed arm entries, the open-field with the distance traveled, and the Y-maze test, where we analyzed the total arm entries (d). The weight of the animals before behavioral assessment ( 21 months old) is represented in e. Error bars represent the SEM. CONT vs PRS $*=p<0.05 ; * *=p$ $<0.01$. Males vs females \# $=p<0.05$; \#\# $=p<0.01$; \#\#\# $=p<$ 0.001

$* p=0.028, n=8-12$ rats/group), but males displayed a higher percentage of errors than females (sex effect: $F_{(1,35)}=4.55$, \#p = 0.04).

Exploratory behavior was assessed in three different tests (Fig. 2d). In the EPM, PRS reduced the number of entries in the closed arm in both sexes (group effect, $F_{(1,35)}=5.147,{ }^{*} p=0.04, n=8-12$ rats/group). In the open-field test, PRS reduced the distance traveled in both sexes ( group effect, $F_{(1,36)}=11.004, * * p=0.002$; $n=8-11$ rats/group). Furthermore, females showed a greater distance traveled than males ( $\operatorname{sex}$ effect, $F_{(1,36)}=$ 20.823, \#\#\#p = 0.00005). The same profile was observed in the Y-maze, where PRS decreased the total arm entries ( group effect, $F_{(1,29)}=11.023$, ** $p=0.0024$; $n=8-9$ rats/group), and females showed increased total 
arm entries compared to males (sex effect, $F_{(1,29)}=$ 4.251, $\# p=0.048$ ). Hence, PRS reduced exploratory behavior in both sexes in all three tests.

The bodyweight of rats (Fig. 2e) was not modified by PRS. However, we observed that female rats weigh less than male rats $\left(\right.$ sex effect, $F_{(1,36)}=79.565$, \#\#\# $p=$ $0.000001, n=8-12$ rats/group).

Effect of sex and PRS on glutamatergic synapses, synaptic vesicle-associated proteins, and stress-/ anti-stress-related proteins in the ventral hippocampus of aged rats

We assessed proteins related to glutamatergic synapses, including metabotropic and ionotropic glutamate receptors and glutamate transporters, synaptic vesicleassociated proteins, and stress-/anti-stress-related proteins in stress-related brain regions (ventral and dorsal hippocampus and prefrontal cortex) and the striatum region.

In the ventral hippocampus, PRS decreased mGlu2/3 receptor protein levels in both sexes ( $g$ roup effect, $F_{(1,17)}$ $=8.472,{ }^{* *} p=0.0097 ; n=5-6$ rats/group) (Fig. 3a). In addition, females, independently of the group, showed reduced $\mathrm{mGlu} 2 / 3$ receptor protein levels compared to males ( ex effect, $F_{(1,17)}=4.827$, \#p = 0.042). PRS reduced mGlu5 receptors (group $\times$ sex effect, $F_{(1,23)}=$ $3.734, p=0.063 ; n=6-7$ rats/group) in males compared to control males (Fisher, $* p=0.049$ ). In addition, control females showed reduced mGlu5 receptors compared to control males (Fisher, $\# p=0.034$ ). Furthermore, females showed a reduction in postsynaptic density protein 95 (PSD95) ( ex effect, $F_{(1,19)}=6.919$, \#p = $0.016 ; n=5-7$ rats/group) (Fig 3a). The GluN1 subunit of NMDA receptors was changed between groups $\left(\right.$ group $\times$ sex effect, $F_{(1,23)}=7.362, p=0.012, n=6-7$ rats/group). The GluN1 was reduced in PRS males (Fisher, $* * p=0.0013$ ) and control females (Fisher, $\# \#$ \# $=0.00018$ ), as compared to control males. In contrast, GluN2A protein levels were increased in females compared to males ( ex effect, $F_{(1,17)}=6.944$, \#p $=0.017 ; n=2-8$ rats/group) (Fig 3b).

Interestingly, female PRS rats showed an opposite profile of VGLUT1 and VGLUT2 expression (Fig 3c), with VGLUT1 ( $n=3-4$ rats/group) being increased (Fisher, $\# p=0.04$ ) and VGLUT2 ( $n=5-8$ rats/group) decreased (Fisher, $\# p=0.028$ ) in PRS females compared to PRS males. $x C T$ protein levels showed significant changes in the ventral hippocampus (group $\times$ sex effect, $F_{(1,22)}=12.394, p=0.0019, n=5-7$ rats/group) and were increased in PRS males (Fisher, $* * p=0.0026$ ) and control females (Fisher, \#\#\#p=0.0008) compared to control males.

For the synaptic vesicle-associated proteins (Fig 3d), we observed a group $\times$ sex interaction for SNAP25 $\left(F_{(1,23)}=6.879, p=0.015, n=6-7\right.$ rats/group $)$, syntaxin $\left(F_{(1,23)}=14.301, p=0.00096, n=6-7 \mathrm{rats} /\right.$ group $)$, and $\operatorname{Rab3a}\left(F_{(1,23)}=5.981, p=0.022, n=6-7\right.$ rats/group $)$ protein levels. PRS decreased the expression of SNAP25 (Fisher, $* * p=0.0051$ ), syntaxin (Fisher, $* * * p=0.00014$ ), and Rab3a (Fisher, $* * p=0.0018$ ), specifically in males. Moreover, we found lower levels of SNAP25 (Fisher, \#\#\#p=0.00007), syntaxin (Fisher, $\# \#$ = 0.00012), and Rab3a (Fisher, \#\# = 0.0034) protein levels in control females compared to control males. In addition, synaptophysin (SYP) protein levels were reduced in females compared to males (sex effect, $F_{(1,22)}=7.73, p=0.011, n=6-7$ rats/group).

Stress-/anti-stress-related proteins were modified by PRS and sex (Fig 3e). GR protein levels showed changes $\left(\right.$ group $\times$ sex effect, $F_{(1,23)}=2.913, p=0.101, n=6-7$ rats/group) and were reduced by PRS only in males (Fisher, $\left.{ }^{*} p=0.014\right)$. The same profile was observed for MR $\left(\right.$ group $\times$ sex effect, $F_{(1,22)}=7.703, p=0.011, n$ = 5-7 rats/group), where PRS males showed a reduction in MR compared to control males (Fisher, $* p=0.021$ ). Interestingly, PRS females showed higher GR (Fisher, $\# p=0.025)$ and MR (Fisher, $\# p=0.031$ ) protein levels than PRS males. OXTR protein levels were also affected $\left(\right.$ group $\times$ sex effect, $F_{(1,23)}=8.325, p=0.0083, n=6-7$ rats/group) and were higher in control females than in control males (Fisher, \#\#p=0.007), but PRS reduced OXTR expression in females (Fisher, $* p=0.02$ ). BDNF levels were increased in females, independent of the group (sex effect, $F_{(1,22)}=6.354, \# p=0.019 ; n=6-7$ rats/group). Representative immunoblots of GR and MR are shown in Fig. 3f. All immunoblots are shown in Supplementary Figs. 1, 2, and 3.

Effect of sex and PRS on glutamatergic synapses, synaptic vesicle-associated proteins, and stress-/ anti-stress-related proteins in the dorsal hippocampus of aged rats

In the dorsal hippocampus (Fig. 4), we found no difference in the mGlu $2 / 3$ protein levels, whereas mGlu 5 receptors were affected by PRS and sex (group $\times$ sex effect, $F_{(1,21)}=13.886, p=0.0012, n=5-7$ rats/group). 


\section{VENTRAL HIPPOCAMPUS}

a. $\mathrm{mGlu}$ receptors and PSD95
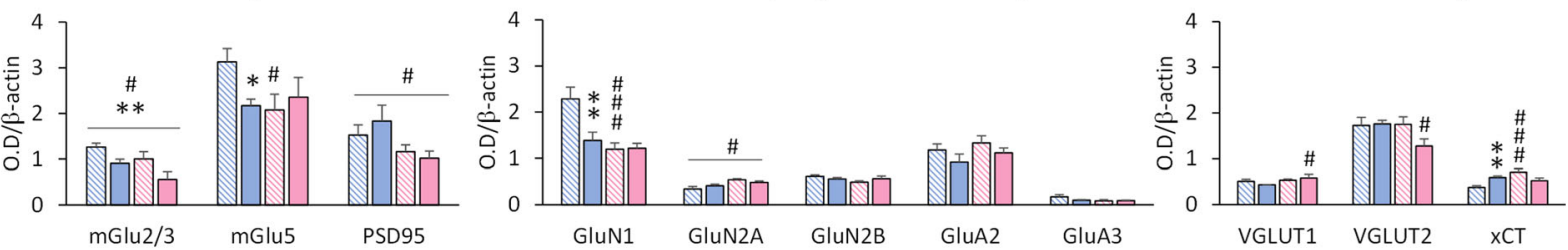

\section{d. Synaptic vesicle-associated proteins}

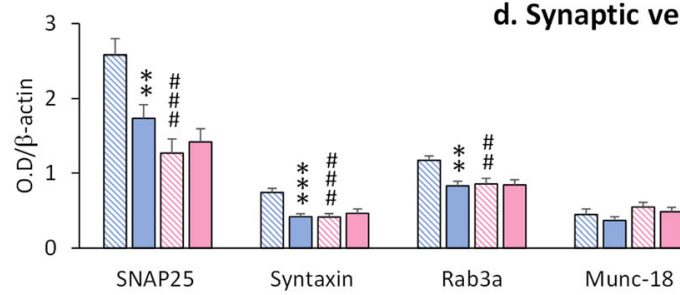

e. Stress/anti-stress related proteins

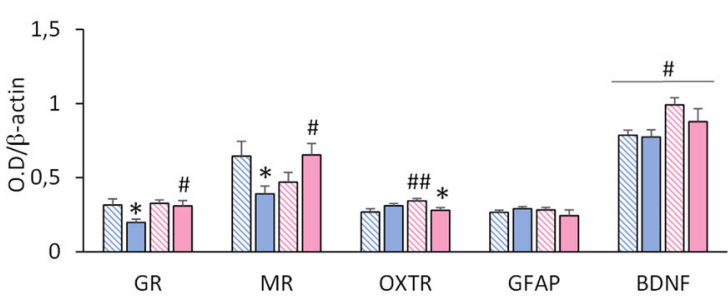

Fig. 3 Effect of sex and PRS on glutamatergic synapses, synaptic vesicle-associated proteins and stress-/anti-stress-related proteins in the ventral hippocampus of aged rats. Immunoblot analysis of the biochemical markers of glutamatergic synapses $(\mathbf{a}, \mathbf{b}, \mathbf{c})$ and synaptic vesicle-associated proteins (d) in synaptosomal fractions collected from the ventral hippocampus of aged male and female

There was a large reduction in mGlu5 receptor protein levels in PRS males (Fisher, $* * * p=0.00003$ ) and control females (Fisher, \#\#\#p=0.000001) compared to control males (Fig. 4a). GluN1 protein levels were reduced in females (sex effect, $F_{(1,23)}=$ 10.308; $p=0.0039, n=6-7$ rats/group). The GluA2 subunit of AMPA receptors was reduced by PRS in both sexes (group effect, $F_{(1,22)}=6.179$, * $p=0.021$; $n=5-9$ rats/group). We also found a group $\times$ sex interaction for GluN2B (group $\times$ sex effect, $F_{(1,21)}=$ 11.696, $p=0.0026, n=4-9$ rats/group), GluA3 $\left(\right.$ group $\times$ sex effect, $F_{(1,22)}=4.964, p=0.036, n=$ five to nine rats/group), VGLUT1 (group $\times$ sex effect, $F_{(1,21)}=10.885, p=0.0034, n=4-9$ rats/group $)$, and $\mathrm{xCT}\left(\right.$ group $\times$ sex effect, $F_{(1,21)}=$ 16.044, $p=0.00064, n=5-7$ rats/group). The post hoc analysis revealed that PRS males displayed reductions in protein levels compared to control males

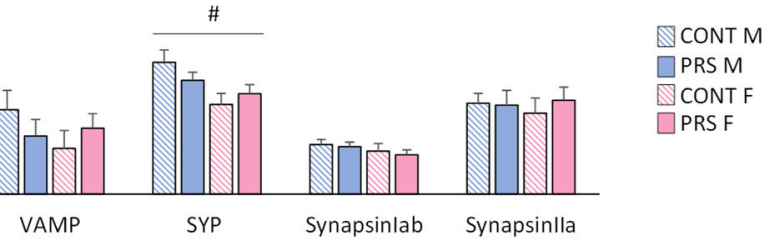

f. Representative immunoblots

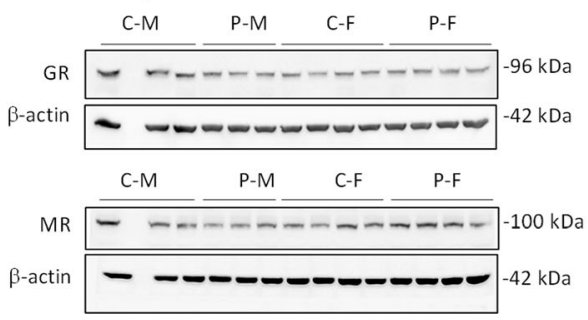

PRS and control (CONT) rats. Immunoblot analysis of stress-/antistress-related proteins in total homogenates (e). Representative immunoblots of GR and MR (f). Error bars represent the SEM images. CONT vs PRS $*=p<0.05$; $* *=p<0.01$; *** $=p<$ 0.001 . Males vs females \# $=p<0.05$; \#\# $=p<0.01$; \#\#\# $=p<$ 0.001

for GluN2B (Fisher, $* * * p=0.00023$ ), GluA3 (Fisher, $* * p=0.0091)$, VGLUT1 (Fisher, $* * * p=$ 0.00024 ), and $\mathrm{xCT}$ (Fisher, $* * * p=0.00084$ ). Similarly, control females showed a reduction in GluN2B (Fisher, \#\#\# = 0.00022), GluA3 (Fisher, $\# p=0.037$ ), VGLUT1 (Fisher, \#\#\# =0.00082), and $\mathrm{xCT}$ (Fisher, $\# p=0.014$ ) compared to control males (Fig. 4b, 4c).

PRS reduced SNAP25 protein levels in both sexes (group effect, $F_{(1,23)}=6.487,{ }^{*} p=0.018 ; n$ =6-7 rats/group). In addition, SNAP25 (sex effect, $F_{(1,23)}=5.484, \# p=0.02$ ) and SYP (sex effect, $F_{(1,23)}=4.956, \# p=0.036 ; n=6-7$ rats $/$ group) protein levels were reduced in females of both groups (Fig. 4d).

MR protein levels were altered (group $\times$ sex effect, $F_{(1,23)}=10.853, p=0.0032, n=6-7$ rats/group) and were higher in PRS males (Fisher, 
DORSAL HIPPOCAMPUS

a. mGlu receptors and PSD95
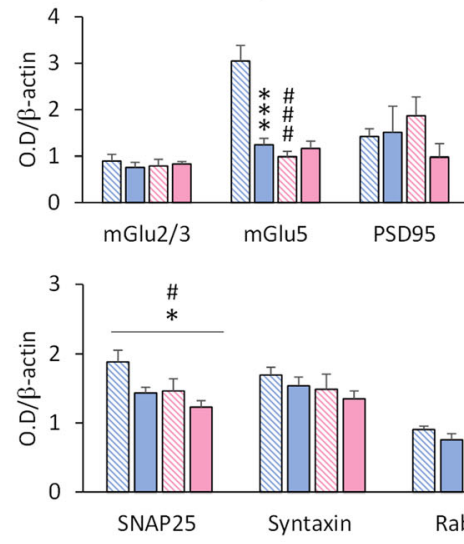

e. Stress/anti-stress related proteins

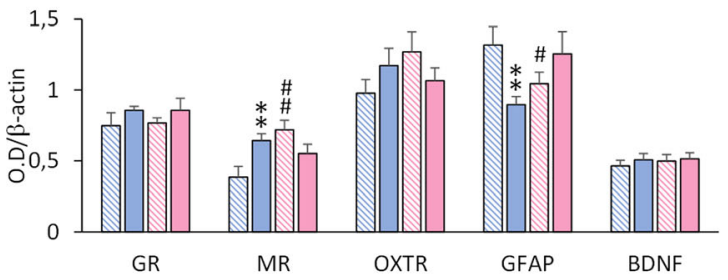

Fig. 4 Effect of sex and PRS on glutamatergic synapses, synaptic vesicle-associated proteins and stress-/anti-stress-related proteins in the dorsal hippocampus of aged rats. Immunoblot analysis of the biochemical markers of glutamatergic synapses $(\mathbf{a}, \mathbf{b}, \mathbf{c})$ and synaptic vesicle-associated proteins (d) in synaptosomal fractions collected from the dorsal hippocampus of aged male and female

$* * p=0.008)$ and control females (Fisher, \#\# $=$ $0.0011)$ than in control males. A sex-dimorphic profile was observed for GFAP (group $\times$ sex effect, $F_{(1,22)}=8.690, p=0.0074, n=5-7$ rats/group $)$. Indeed, PRS reduced GFAP expression only in males (Fisher, ${ }^{* *} p=0.0081$ ), while GFAP expression was increased in PRS females (Fisher, \#p= 0.034) compared to PRS males (Fig. 4e). Representative immunoblots of GR and MR are shown in Fig. 4f. All immunoblots are shown in Supplementary Figs. 4, 5, and 6.

Protein levels of aromatase, an enzyme that converts testosterone into estradiol [51], were analyzed in the dorsal hippocampus by western blot (Fig. 4g). We observed a sex-dimorphic profile induced by PRS (group $\times$ sex effect, $F_{(1,23)}=12.071, p=0.0021 ; n=6-7$ rats/group). PRS increased aromatase levels in males compared to control males (Fisher, ${ }^{*} p=0.0062$ ) and c. Glutamate transporters

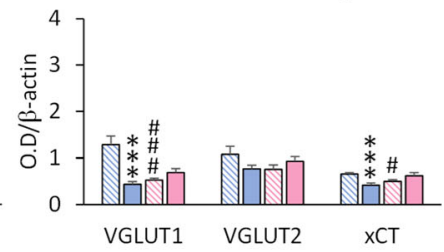

$\mathbb{Q}$ CONT M

$\square$ PRS M

$\mathbb{Q}$ CONT F

$\square$ PRS F

g. Aromatase
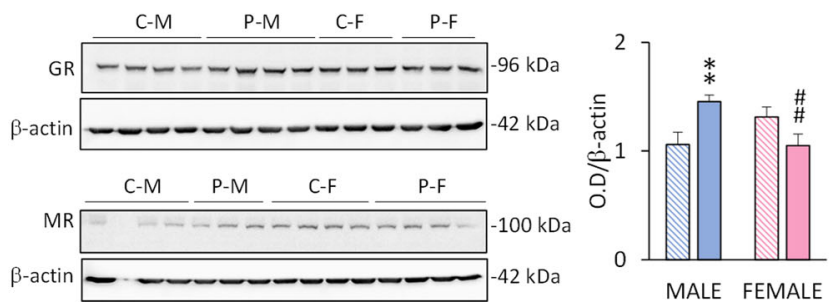

PRS and control (CONT) rats. Immunoblot analysis of the stress-/ anti-stress-related proteins in total homogenates (e). Representative immunoblots of GR and MR (f). Immunoblot analysis of aromatase (g). Error bars represent the SEM images. CONT vs PRS $*=p<0.05 ; * *=p<0.01 ; * * *=p<0.001$. Males vs females $\#=p<0.05 ; \# \#=p<0.0 ; \# \#=p<0.001$

reduced levels in PRS females (Fisher, \#\# = 0.0071) compared to PRS males.

Effect of sex and PRS on glutamatergic synapses, synaptic vesicle-associated proteins, and stress-/ anti-stress-related proteins in the prefrontal cortex of aged rats

In the prefrontal cortex (Fig. 5), we observed a reduction in $\mathrm{mGlu} 2 / 3$ receptor protein levels in response to PRS (group effect, $F_{(1,22)}=13.858, * * p=0.0011, n=6$ 7 rats/group) and in female rats (sex effect, $F_{(1,22)}=$ 7.436, $\# p=0.012, n=6-7$ rats/group). mGlu5 receptors were also reduced (group $\times$ sex effect, $F_{(1,22)}=3.093, p$ $=0.093, n=6-7$ rats/group). In particular, we found a reduction in PRS males (Fisher, $* p=0.02$ ) and control females (Fisher, $\# p=0.035$ ) compared to control males. Moreover, PSD95 protein levels were decreased by PRS 


\section{PREFRONTAL CORTEX}

a. mGlu receptors and PSD95

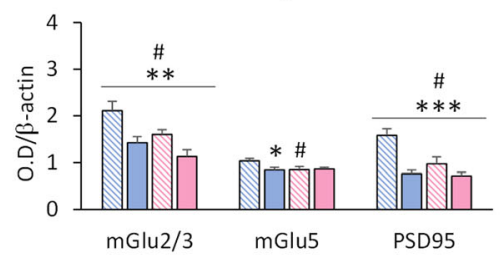

b. Ionotropic glutamate receptors

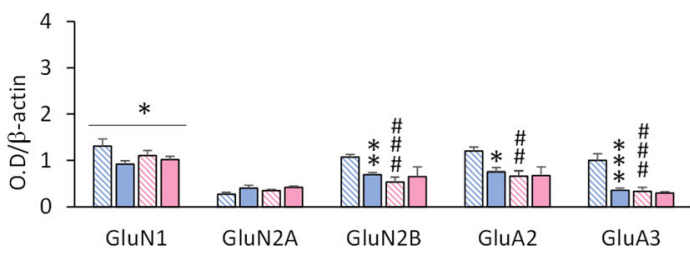

c. Glutamate transporters

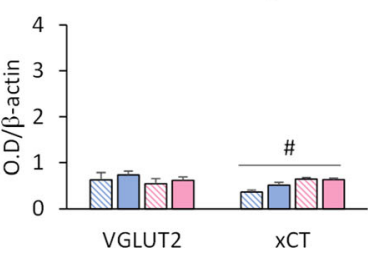

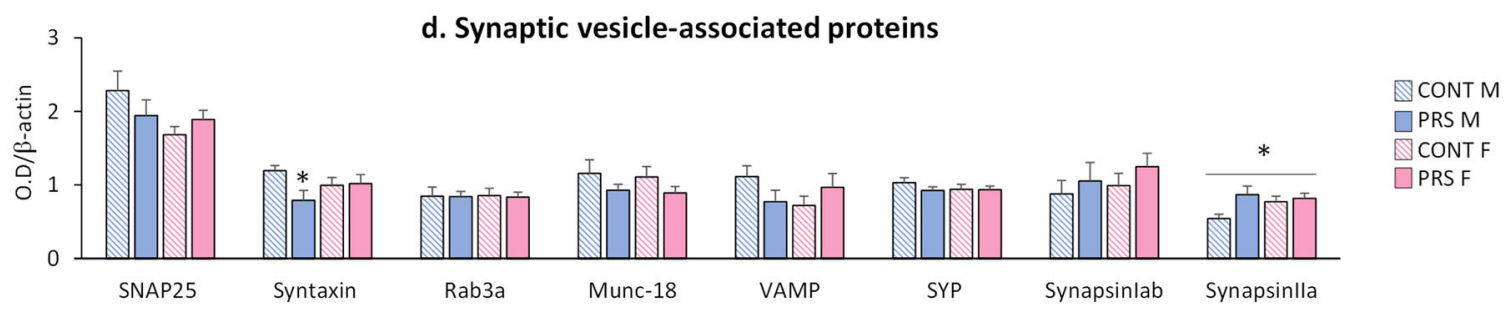

e. Stress/anti-stress related proteins

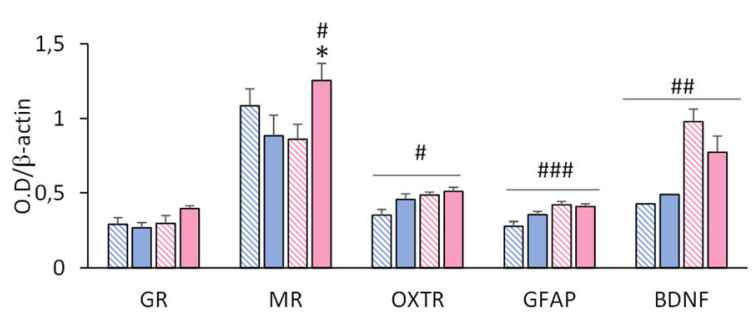

Fig. 5 Effect of sex and PRS on glutamatergic synapses, synaptic vesicle-associated proteins and stress-/anti-stress-related proteins in the prefrontal cortex of aged rats. Immunoblot analysis of biochemical markers of glutamatergic synapses $(\mathbf{a}, \mathbf{b}, \mathbf{c})$ and synaptic vesicle-associated proteins $(\mathbf{d})$ in synaptosomal fractions collected from the prefrontal cortex of aged male and female PRS

( group effect, $F_{(1,22)}=25.134,{ }^{* * *} p=0.00005 ; n=6-7$ rats/group) and in female rats (sex effect, $F_{(1,22)}=5.47$, $\# p=0.029 ; n=6-7 \mathrm{rats} /$ group) (Fig. 5a). PRS also reduced GluN1 protein levels in both sexes (group effect, $F_{(1,22)}=5.615,{ }^{*} p=0.027 ; n=6-7$ rats/group). A group $\times$ sex interaction was found for (GluN2B $\left(F_{(1,18)}=6.658, p=0.019, n=4-7\right.$ rats $/$ group $)$, GluA2 $\left(F_{(1,20)}=3.494, p=0.076 ; n=6-7\right.$ rats/group $)$, and GluA3 $\left(F(1,22)_{1,1}=1.528, p=0.0026 ; n=5-7\right.$ rats/group). PRS males displayed a reduction in protein expression compared to control males for GluN2B (Fisher, ${ }^{* *} p=0.0045$ ), GluA2 (Fisher, ${ }^{*} p=0.016$ ), and GluA3 (Fisher, ${ }^{* * *} p=0.00001$ ). Similarly, control females showed reduced GluN2B (Fisher, \#\#\# = 0.00096), GluA2 (Fisher, \#\# = 0.0059), and GluA3 (Fisher, \#\#\# = 0.00004) protein levels, compared to control males (Fig. 5b). Furthermore, females of both groups showed an increase in XCT protein levels (sex

\section{f. Representative immunoblots}

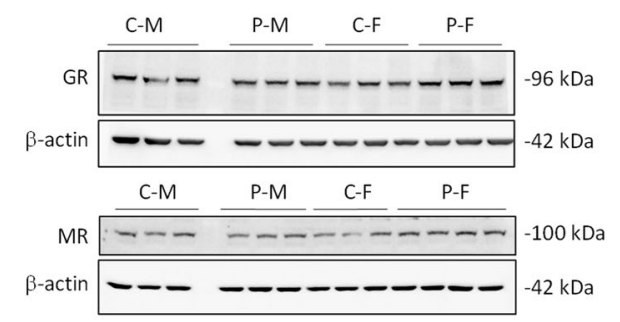

and control (CONT) rats. Immunoblot analysis of the stress-/antistress-related proteins in total homogenates (e). Representative immunoblots of GR and MR (f). Error bars represent the SEM images. CONT vs PRS * $=p<0.05$; ** $=p<0.01$; *** $=p<$ 0.001. Males vs females \# $=p<0.05$; \#\# $=p<0.01$; \#\#\# $=p<$ 0.001

effect, $F_{(1,19)}=5.76, \# p=0.027 ; n=4-7$ rats/group) (Fig. 5c).

Few changes in the synaptic vesicle-associated with the prefrontal cortex were observed (Fig. 5d). Syntaxin expression was changed $\left(\right.$ group $\times$ sex effect, $F_{(1,23)}=$ $14.301, p=0.067, n=6-7$ rats/group) and reduced in PRS males compared to control males (Fisher, $* p=$ 0.015). In contrast, synapsin IIa expression was increased by PRS in both sexes (group effect, $F_{(1,23)}=$ $5.318, * p=0.011 ; n=6-7$ rats/group).

MR protein levels were altered (group $\times$ sex effect, $F_{(1,20)}=6.486, p=0.019, n=6$ rats/group) and were increased in PRS females compared to PRS males (Fisher, ${ }^{*} p=0.036$ ) and control females (Fisher, $\# p=0.028$ ). Furthermore, females of both groups displayed greater OXTR protein levels ( ex effect, $F_{(1,19)}=8.829$, \#p = $0.01 ; n=5-6$ rats/group). Interestingly, we found a higher expression of BDNF $\left(\right.$ sex effect, $F_{(1,20)}=$ 
13.705, \#\#p = 0.0014; $n=6$ rats/group) and GFAP (sex effect, $F_{(1,19)}=16.466$, \#\#\#p $=0.00067 ; n=6$ rats/group) in females of both groups (Fig. 5e). Representative immunoblots of GR and MR are shown in Fig. 5f. All immunoblots are shown in Supplementary Figs. 7,8 , and 9 .

Effect of sex and PRS on glutamatergic synapses and synaptic vesicle-associated proteins in the striatum of aged rats

In the striatum (Fig. 6), PSD95 protein levels were reduced $\left(\right.$ group $\times$ sex effect, $F_{(1,18)}=11.978, p=$ $0.0028 ; n=4-7$ rats/group) in PRS males (Fisher, $* * p$ $=0.0013$ ) and control females (Fisher, \#\#\#=0.00009) compared to control males (Fig. 6a). Moreover, PRS increased GluN1 ( group $\times$ sex effect, $F_{(1,23)}=5.24, p=$ $0.032, n=6-7$ rats/group) only in females (Fisher, \#\#p = 0.0056). GluA2 was decreased in females of both groups (sex effect: $F_{(1,18)}=4.872, \# p=0.04 ; n=4-6$ rats/group) (Fig. 6b). Concerning VGLUT2 protein levels, we found a sex-dimorphic profile, which was inverted by PRS ( group $\times$ sex effect, $F_{(3,18)}=9.119, p$ $=0.0074 ; n=4-7$ rats/group). PRS decreased VGLUT2 in males (Fisher, $* p=0.035$ ) but increased VGLUT2 in females (Fisher, \#\#p =0.0036) compared to control male and PRS male rats, respectively (Fig. 6c).

Synaptic vesicle-associated proteins were modified by sex and PRS (Fig. 6d). We observed a group $\times$ sex interaction for the expression of SNAP25 $\left(F_{(1,23)}=\right.$ $8.441, p=0.008 ; n=6-7$ rats/group $)$, Munc-18 $\left(F_{(1,23)}\right.$ $=4.26, p=0.05 ; n=5-7$ rats $/$ group $)$, and $\operatorname{VAMP}\left(F_{(1,21)}\right.$ $=11.51, p=0.0027 ; n=5-7$ rats/group). PRS males displayed a reduction in Rab3a (Fisher, ${ }^{*} p=0.016$ ), Munc-18 (Fisher, $* p=0.017$ ), and VAMP (Fisher, $* p=$ $0.015)$ protein levels compared to control males. Moreover, control females showed reduced SNAP25 protein levels (Fisher, \#\# = 0.0022). Similarly, protein levels of synapsin Iab were modified (group $\times$ sex effect, $F_{(1,24)}=11.51, p=0.074 ; n=7$ rats/group) and were increased in PRS females (Fisher, $* p=0.02$ ) compared to control females. Representative immunoblots of SNAP25 and Munc-18 are shown in Fig. 6f. All immunoblots are shown in Supplementary Figs. 10 and 11.

Multidimensional analysis

Consecutively with the western blot analysis, we performed a multidimensional analysis with all the protein data obtained in each structure to analyze the effect of PRS and sex on the protein data set more comprehensively.

The multidimensional analyses revealed a demasculinization profile of the glutamatergic synapse induced by PRS in the ventral hippocampus (Fig. 7a; demasculinization score, 1.41; Mann-WhitneyWilcoxon test, $p=0.002 ; n=5-7$ rats/group), in the dorsal hippocampus (Fig. 7b; demasculinization score, 1.55; Mann-Whitney-Wilcoxon test, $p=0.0006 ; n=5$ 9 rats/group) as well as in the prefrontal cortex (Fig. 7c; demasculinization score, 1.50; Mann-WhitneyWilcoxon test, $p<0.0001 ; n=6-7$ rats/group) but not in the striatum (Fig. 7d; demasculinization score, 1.26; Mann-Whitney-Wilcoxon test, $p=0.06 ; n=6-7$ rats/group). PRS did not induce a global defeminization profile of glutamatergic synapses in any of the brain regions studied. Of note, multidimensional analyses performed on the stress-/anti-stress-related protein data set revealed that PRS induced a defeminization profile only in the ventral hippocampus (defeminization score, 1.71; Mann-Whitney-Wilcoxon test, $p=0.004 ; n=5-7$ rats/group) (Supplementary Fig. 12a) and a demasculinization profile exclusively in the dorsal hippocampus (demasculinization score, 1.73; Mann-Whitney-Wilcoxon test, $p=0.001 ; n=5-9$ rats/group) (Supplementary Fig. 12b). Thus, demasculinization could be observed only for proteins related to glutamatergic transmission.

Effect of sex and PRS on sex hormones and peripheral markers in aged male and female rats

We assessed plasma testosterone and estradiol levels (Fig. 8a, 8b). We found a significant reduction in testosterone levels in response to PRS in both sexes (group effect, $F_{(1,24)}=5.882,{ }^{*} p=0.023 ; n=5-9$ rats/group). Moreover, females displayed lower levels of testosterone than males ( $\operatorname{sex}$ effect, $F_{(1,24)}=4.42, \# p=0.046 ; n=$ 5-9 rats/group) (Fig. 8a). Estradiol levels in the plasma revealed a group $\times$ sex interaction $\left(F_{(1,21)}=5.3, \$ p=\right.$ $0.032 ; n=4-8$ rats/group) where PRS females showed lower levels of estradiol than control females (one-way ANOVA, $* * * p=0.00021$ ) and PRS males (one-way ANOVA, $\# p=0.034$ ) (Fig. 8 b).

We also measured plasma levels of IL-6 and oxytocin as peripheral markers of inflammation and resilience to stress, respectively (Fig. 8c, 8d). We found a group $\times$ sex interaction for IL-6 levels $\left(\right.$ group $\times$ sex effect, $F_{(1,20)}$ 
STRIATUM

a. mGlu receptors and PSD95

b. Ionotropic glutamate receptors

c. Glutamate transporters
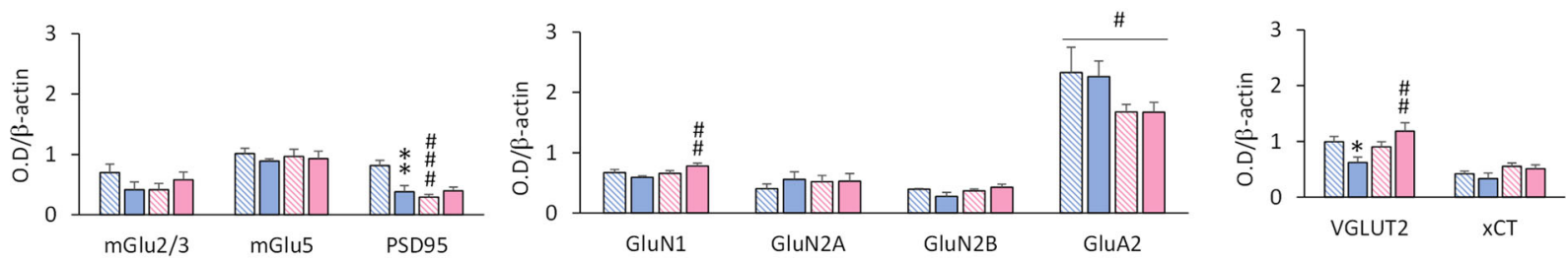

d. Synaptic vesicle-associated proteins

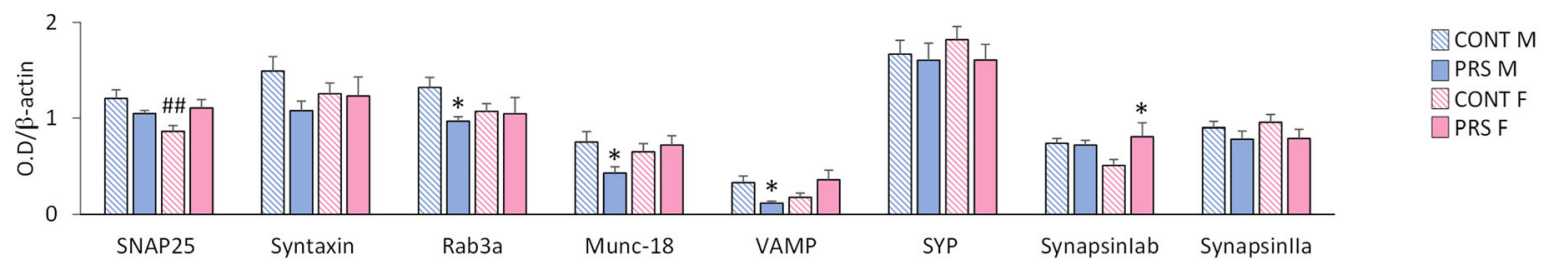

e. Representative immunoblots

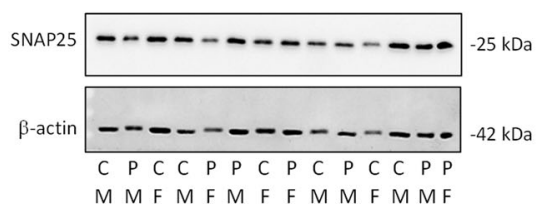

Fig. 6 Effect of sex and PRS on glutamatergic synapses and synaptic vesicle-associated proteins in the striatum of aged rats. Immunoblot analysis of biochemical markers of glutamatergic synapses $(\mathbf{a}, \mathbf{b}, \mathbf{c})$ and synaptic vesicle-associated proteins $(\mathbf{d})$ in synaptosomal fractions collected from the striatum of aged male

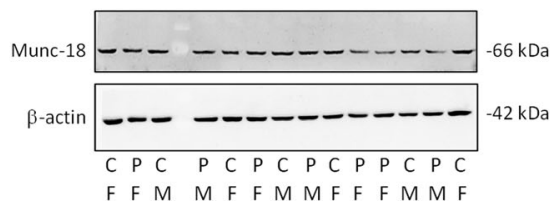

and female PRS and control (CONT) rats. Representative immunoblots of SNAP-25 and Munc-18 (e). Error bars represent the SEM images. CONT vs PRS $*=p<0.05$; $* *=p<0.01$; males vs females \# $=p<0.05$; \#\# $=p<0.01$; \#\#\# $=p<0.001$

\section{Discussion}

We showed that perinatal stress programs lifelong changes in mechanisms that help to balance vulnerability and resilience to stress. Indeed, non-genetic factors such as stress occurring early in life are known to act as perinatal "programming" because they critically contribute to several aspects of the adult phenotype. This concept is based on Barker's theory of the evolutionary origins of adult health and disease (DOHaD). This theory defines the relationship between early developmental influences on health and disease in adulthood and aging [52-54]. We observed that long-term programming was sex-dependent in both non-stressed and PRS aged rats. At a behavioral level, PRS increased risktaking behavior in females but decreased it in males. These results are similar to those observed in adult (3-6 month old) rats [32], indicating that the sex-dependent programming induced by PRS is persistent and uniform. While PRS impaired spatial memory in males, no 


\section{Multidimensional analyses}

\section{a. PCA-Ventral hippocampus}

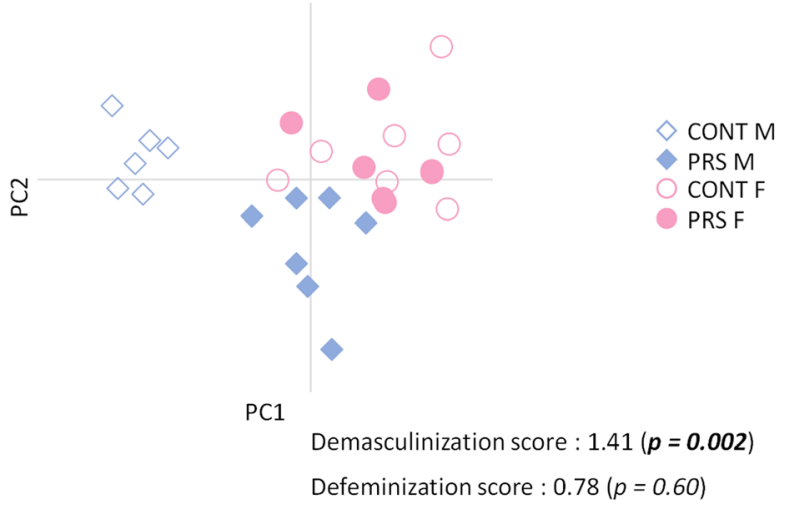

c. PCA-Prefrontal cortex

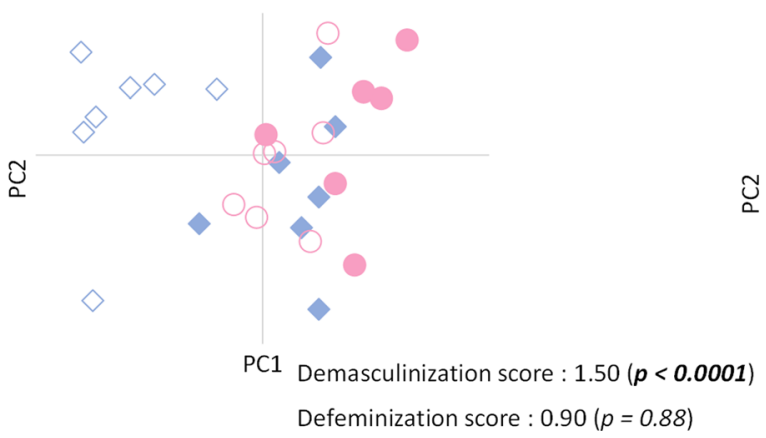

Fig. 7 Multidimensional analyses. Multidimensional analysis of the protein data set (markers of the glutamatergic synapse, synaptic vesicles-associated proteins, and stress-/anti-stress-related

changes were observed in females. These results are also consistent with previous findings obtained in males [16] and suggest that females are resilient to maladaptive neuroplasticity changes caused by early-life stress. Motor performance declines with aging, as shown by increased variability of movement [55], slowing of movement [56], altered coordination [57], and difficulties with balance and gait [58]. Using the ladder rungwalking test, we showed that PRS increased the number of errors predominantly in males, lending credit to the hypothesis that aged females cope better with PRS, even if PRS decreased exploratory behavior in the EPM, Ymaze, and open-field tests equally in both sexes.

Impressively, these alterations were associated with large reductions in biochemical markers of the glutamatergic synapse in the hippocampus (ventral and dorsal) and prefrontal cortex, which were exclusively seen in males. PRS decreased both the mGlu5 receptor and GluN1 subunit protein levels in male rats. A similar b. PCA-Dorsal hippocampus

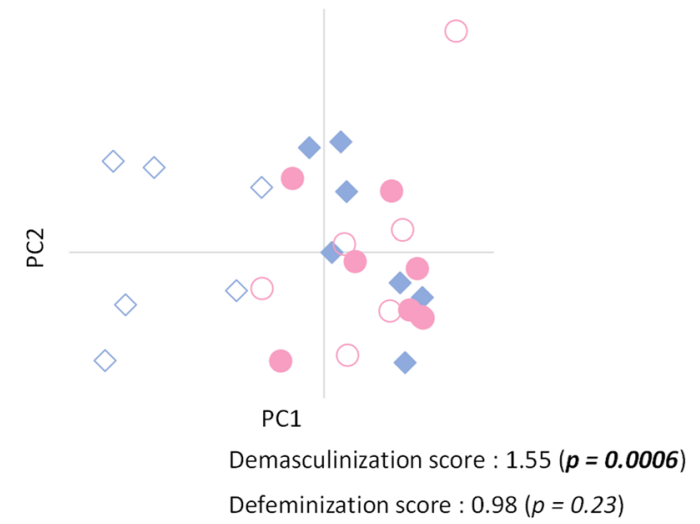

d. PCA-Striatum

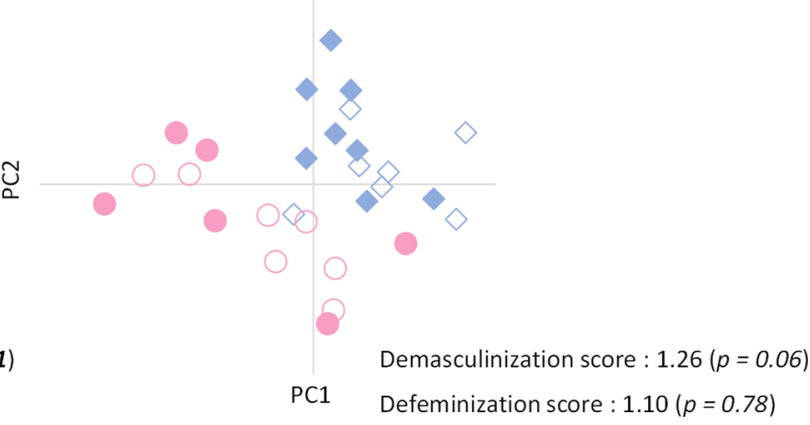

proteins) of the ventral hippocampus (a), dorsal hippocampus (b), prefrontal cortex (c), and striatum (d). PCA, principal component analysis

scenario was reported in adult rats, in which PRS reduced hippocampal mGlu5 receptors only in males [32]. mGlu5 and NMDA receptors are physically linked by a chain of scaffolding proteins and functionally interact in the induction of activity-dependent synaptic plasticity $[59,60]$. Changes in mGlu5 and NMDA receptors found in this study are in agreement with previous data observed in adult PRS male rats [61] and suggest that PRS impairs the receptor substrates of synaptic plasticity in aged male rats. Interestingly, the lowering effect of PRS on mGlu2/3 receptor protein levels in the ventral hippocampus and prefrontal cortex of aged rats was not sex-dependent, whereas it was sex-dependent in nonstressed control rats, with control females showing reduced $m G l u 2 / 3$ protein levels as compared to control males. Again, the PRS effects were similar to those reported in the whole hippocampus of adult rats, where PRS reduced mGlu2 $/ 3$ receptor protein levels in both sexes [32]. Activation of the $m G l u 2 / 3$ receptors with the 


\section{Peripheral markers}

a. Plasma testosterone levels

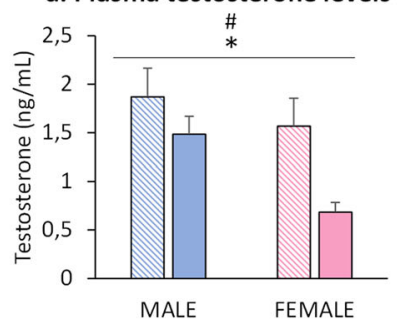

b. Plasma estradiol levels

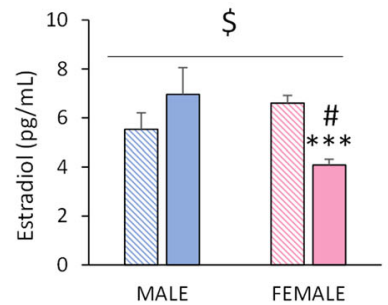

c. Plasma interleukin-6 levels

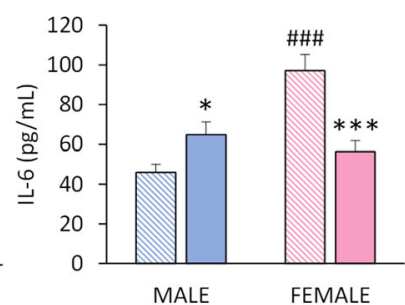

d. Plasma oxytocin levels

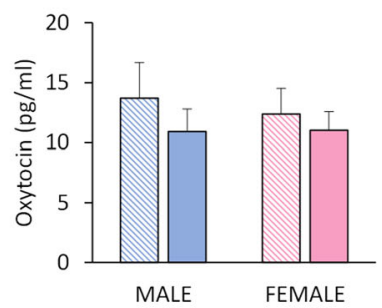

Partial correlations

e. EPM exploratory behavior and testosterone

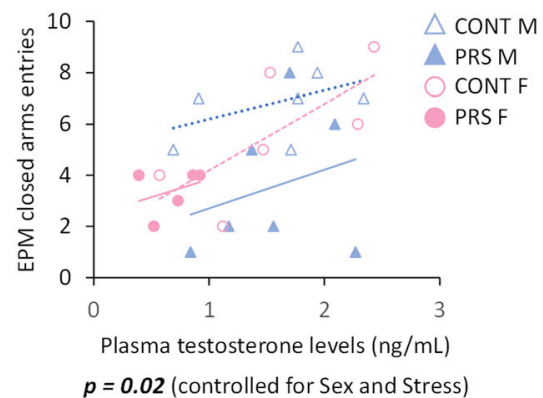

f. EPM risk-taking behavior and IL-6

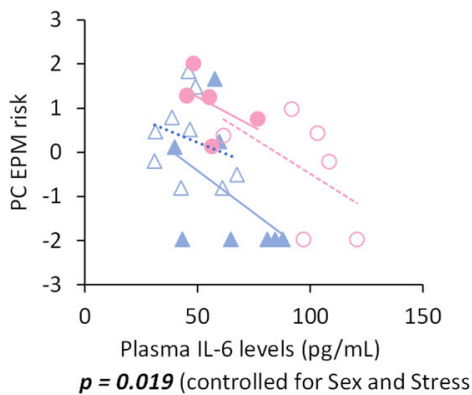

g. EPM risk-taking behavior and oxytocin

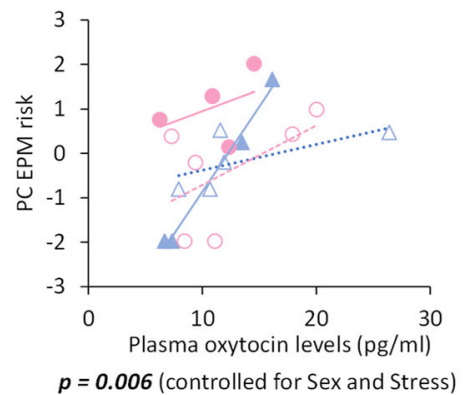

Fig. 8 Effect of sex and PRS on sex hormones and peripheral markers in aged male and female rats. Plasma levels of testosterone $(\mathrm{ng} / \mathrm{mL})(\mathbf{a})$, estradiol $(\mathrm{pg} / \mathrm{mL})(\mathbf{b})$, interleukin-6 ( $\mathrm{pg} / \mathrm{mL})(\mathbf{c})$, and oxytocin $(\mathrm{pg} / \mathrm{mL})$ (d). Partial correlation between exploratory behavior in the EPM and testosterone levels is shown in e. Partial

agonist, LY354740, induces increased risk-taking behavior in male rats $[62,63]$. mGlu2/3 receptors are targets for drug treatment of anxiety and other stressrelated disorders in humans [64]. Here, reduced mGlu2/ 3 receptor expression was associated with decreased exploratory behavior in PRS rats of both sexes. mGlu2/3 receptors are preferentially localized in presynaptic terminals and are known to negatively regulate glutamate release [65]. Using adult rats, we found that PRS reduces glutamate release in the ventral hippocampus [26]. Hence, the reduction in mGlu2/3 receptor expression seen during early-life [66], adult life [32], and aging (present data) could represent an allostatic compensatory mechanism, which operates across the entire lifespan. One of the most interesting findings related to a possible hypofunction of the glutamatergic synapse in PRS males was the reduction of NMDA and AMPA receptor subunits. NMDA and AMPA receptors are ligand-gated ion channels involved in the induction and expression of long-term potentiation and long-term correlation between risk-taking behavior and IL-6 is represented in f. Partial correlation between risk-taking behavior and oxytocin levels is shown in g. Error bars represent the SEM. CONT vs PRS $*=p<0.05 ; * * *=p<0.001$. Males vs females $\#=p<0.05$; \#\#\#= $p<0.001$

depression of excitatory synaptic transmission, respectively [67, 68]. In agreement with our results, it has been reported that early-life stress impairs the development of synaptic plasticity in the CA1 hippocampal region in a sex-dependent manner, with males being more vulnerable [69]. Furthermore, a decrease in GluN2B following early-life stress has been reported in the hippocampus [70]. Interestingly, $\mathrm{xCT}$ protein levels in PRS male rats differed between the dorsal and ventral hippocampi. $\mathrm{xCT}$ protein levels in male rats were increased in the ventral hippocampus and decreased in the dorsal hippocampus in response to PRS. $\mathrm{xCT}$ is the catalytic subunit of $X_{c}^{-}$, the cysteine glutamate antiporter that supports the endogenous activation of presynaptic mGlu2 receptors by enhancing glutamate efflux from astrocytes [71]. $\mathrm{xCT}$ in the hippocampal dentate gyrus has been implicated in the mechanisms of resilience to stress [72], and changes in glutamate homeostasis in response to stress differ between the ventral and dorsal hippocampi [26, 72]. Hence, the differential expression of $\mathrm{xCT}$ in the 
ventral and dorsal hippocampus of PRS rats could help explain the greater involvement of the ventral hippocampus in the "pathological" phenotype triggered by PRS.

Glutamatergic neurotransmission is also regulated by the expression and function of synaptic vesicle-related proteins involved in glutamate release [73, 74]. Synaptic vesicle-associated proteins were decreased by PRS in the ventral hippocampus and striatum of male rats, suggesting that PRS predisposes to long-term dysfunction of the release machinery in aged rats. The hypofunction of glutamate transmission observed in the ventral hippocampus of aged male PRS rats is in agreement with previous results obtained in adult male PRS rats $[26,27,75]$. This supports the hypothesis that long-lasting alterations in the glutamate synapse in the ventral hippocampus lie at the core of the programming triggered by PRS.

Compared to males, females showed reduced body weight regardless of early-life stress. This may have a potential impact on the sex-specific dimorphic profile observed in aged rats. Indeed, it has been shown that caloric restriction and subsequent weight loss during aging could prevent the reprogramming of daily rhythms in mice caused by aging [76]. The reduced body weight in females, associated with increased levels of BDNF and MR, supports neuroprotection. PRS did not induce changes in body weight in both sexes during aging. This was not surprising because we have previously shown that PRS induced caloric restriction and reduced body weight at birth but not in adult life [77]. The recovery of body weight after early postnatal life in PRS rats might reflect adaptive mechanisms driven by growth-related metabolic alterations in these rats $[30$, 31, 77-79].

Glucocorticoids regulate glutamate transmission via MRs and GRs [22, 80, 81]. A link between MRs and mGlu receptors is suggested by evidence that glucocorticoids, acting via MRs, decrease resilience to stress by downregulating mGlu2 receptors [82]. The activation of GRs by glucocorticoids mediates the negative feedback of the HPA axis. Therefore, decreased GR and MR expression contribute to the long-lasting dysregulation of the HPA axis. Accordingly, prolonged corticosterone secretion following acute stress associated with reduced GR/MR protein levels in the hippocampus has been found in male adult PRS rats $[15,20]$. In addition, circulating glucocorticoid levels in PRS middle-aged male [16] and female [30, 31] rats were similar to those of old non-stressed control rats, suggesting that PRS accelerates the age-related dysfunction of the HPA axis $[16,30,31,83,84]$. Here, we showed that PRS decreased GR and MR protein levels in the ventral hippocampus of male rats, whereas MR levels were increased in female rats. This suggests that PRS female rats are more protected than PRS male rats against the accelerated age-related dysfunction of the HPA axis. Furthermore, impairment of the HPA axis in aged PRS rats may be involved in the programming of a long-lasting hypofunction of the glutamatergic synapse ([26]; and present data). Oxytocin acts as an anti-stress hormone $[25,85,86])$ and supports maternal care [46, 86, 87]. Although plasma oxytocin levels were unchanged by PRS in both sexes, we observed increased oxytocin receptors in the prefrontal cortex of female PRS rats, indicating increased oxytocinergic transmission. BDNF is another key factor in the stress response. Like oxytocin, BDNF has anti-stress effects, as shown by evidence that the overexpression of BDNF occludes the effects of chronic stress [88] and chronic stress decreases BDNF levels [89]. BDNF-mediated signaling is involved in the structural effects of stress and plays an important role in dendritic remodeling $[90,91]$. In addition, BDNF expression is influenced by maternal separation early in life [92]. GFAP levels in the dorsal hippocampus were increased by PRS in females and reduced in males. GFAP is an astrocyte-specific intermediate filament protein [93, 94], which increases during reactive astrogliosis associated with neurodegeneration.

Multidimensional analyses of the overall data on protein expression showed that PRS in male rats induced a "demasculinization profile" of glutamatergic transmission and synaptic vesicle-related proteins in the ventral and dorsal hippocampus and prefrontal cortex, the main regions related to stress [95], but not in the striatum. In contrast, PRS did not alter the profile in female rats. That is, it did not induce defeminization. These findings are consistent with previous data obtained in adult rats [42]. Thus, PRS demasculinizes rather than defeminizes, and indeed male PRS rats exhibited a profile similar to that of female PRS rats. Indeed, masculinization or feminization allows for the capacity to express sex-specific profiles in adulthood, and demasculinization or defeminization eliminates or reduces the capacity to express sex-specific profiles in adulthood. Demasculinization might reflect changes in sex steroid hormones. Indeed, PRS males showed decreased testosterone and increased estradiol levels in 


\section{Sex differences in the aged brain}

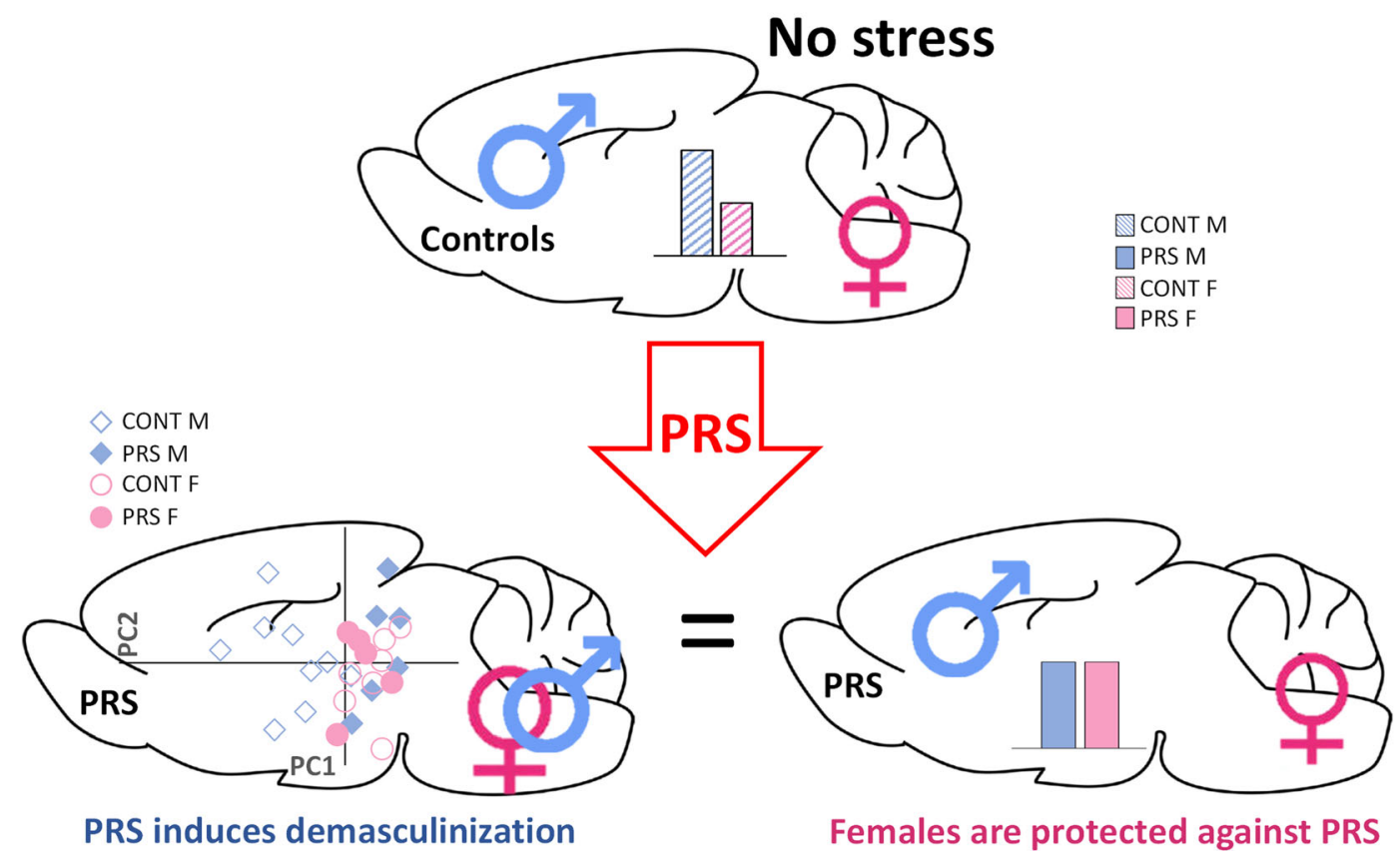

Fig. 9 Graphical abstract. Aged male and female control rats display sex differences in the brain. PRS induces brain demasculinization, thereby abolishing sex differences. PRS does not affect females as much as males during aging, suggesting that

females are protected against PRS. Males are represented in blue, and females are represented in pink. $\mathrm{E}=$ embryologic day; $\mathrm{P}=$ postnatal day

plasma. A reduction in testosterone levels might represent a lifelong endocrine outcome of PRS in male rats because it was observed in fetal and adult life after maternal stress [29, 37, 43]. Thus, the sex hormonal change induced by PRS could be taken into account in relation to the demasculinization of the glutamatergic system observed during old age. The higher GFAP levels found in the prefrontal cortex of aged female rats in both groups were associated with lower testosterone levels compared to male rats. However, this association was not found in the dorsal hippocampus of PRS male rats, where GFAP levels were largely reduced despite the reduction in plasma testosterone levels compared to unstressed male rats. Thus, changes in GFAP expression driven by sex and PRS in aged rats appear to be brain region-dependent and might reflect a complex interaction between peripheral sex steroids and intrinsic brain mechanisms. Interestingly, we found that aromatase, the enzyme that converts testosterone to estradiol, was upregulated by PRS in males and downregulated in females in the dorsal hippocampus but not in the ventral hippocampus or prefrontal cortex (data not shown),

supporting the region-specific regulation of GFAP by sex steroids.

Glucocorticoids and the immune system are tightly linked, and alterations in the immune system were found to be induced by PRS in adult life, as shown by a pro-inflammatory state [18]. Here, we found that PRS increased IL-6 levels in males but caused the opposite effect in females. It is known that IL-6 levels increase with age in both rats [96] and humans [97]. Thus, our findings suggest that females are protected against systemic inflammation during aging, which is caused by early-life stress. Interestingly, rats with higher levels of IL-6 showed reduced risk-taking behavior in the EPM test, and this negative correlation is in line with the current belief that inflammation highly contributes to behavioral changes associated with age and age-related disorders. Finally, the levels of the anti-stress hormone, oxytocin, which corrects behavioral and biochemical abnormalities caused by PRS in adult rats [46], showed a positive correlation with risk-taking behavior, supporting the view that oxytocin has a 
protective effect against the increased vulnerability to stress caused by PRS.

In conclusion, our findings provide the first evidence that the effects of PRS are long-term programmed and sex-dependent. PRS induces a demasculinization profile of glutamate and synaptic vesicle-related proteins in aged male rats but not defeminization in female rats. The early-lifelong programming induced by PRS strongly supports Barker's hypothesis of adult health and disease (DOHaD). In aged PRS females, the lower systemic levels of the pro-inflammatory cytokine, IL-6, and the higher levels of BDNF in stress-related brain regions might be components of an adaptive mechanism aimed at restraining age-dependent neuroinflammation and neurodegeneration. Along this line, demasculinization observed in PRS male rats might reflect an allostatic load reaction against PRS, as hypothesized in Fig. 9. This kind of studies aimed at understanding the mechanisms involved in the programming of aging in both sexes may contribute to identifying early environmental factors and pharmacological treatment strategies involving glutamate transmission. Finally, due to people living longer, and thus, the population of elderly growing worldwide, such studies could help improve older adults' quality of life.

Supplementary Information The online version contains supplementary material available at https://doi.org/10.1007/s11357021-00375-5.

Acknowledgements Most of the behavioral assessments were carried out using the animal and experimental facility PHExMAR of the University of Lille. We would like to thank the Research Federation FRABio (Univ. Lille, CNRS, FR 3688, FRABio, Biochimie Structurale et Fonctionnelle des Assemblages Biomoléculaires) for providing a scientific and technical environment that was conducive to completing this study. English editing was provided by Editing Elsevier services.

Author contribution S.M., F.N., S.M.F., and R.V. designed the experiments. R.V. performed the behavioral and biochemical experiments and their analysis. V.G. performed the bioinformatics analysis. H.B. provided additional bioinformatics support. G.V.C. was involved in animal sacrifice and brain dissection. R.V. and S.M. wrote the first draft of the paper. S.M., F.N., S.M.F, F.C., and V.G. edited the manuscript. All authors have read and approved the final manuscript.

Funding This study was supported by (1) the University of Lille, Sapienza University of Rome (Framework Agreement signed on February 15th, 2007); (2) Neuromed IRCCS (funds by the Italian Ministry of Health); and (3) the CNRS within the framework of the Prenatal Stress and Neurodegenerative Diseases International Associated Laboratory (LIA-PSND), co-directed by Professors S. Maccari and F. Nicoletti.

\section{Declaration}

Conflict of interest The authors declare no competing interests.

Open Access This article is licensed under a Creative Commons Attribution 4.0 International License, which permits use, sharing, adaptation, distribution and reproduction in any medium or format, as long as you give appropriate credit to the original author(s) and the source, provide a link to the Creative Commons licence, and indicate if changes were made. The images or other third party material in this article are included in the article's Creative Commons licence, unless indicated otherwise in a credit line to the material. If material is not included in the article's Creative Commons licence and your intended use is not permitted by statutory regulation or exceeds the permitted use, you will need to obtain permission directly from the copyright holder. To view a copy of this licence, visit http://creativecommons.org/licenses/by/4.0/.

\section{References}

1. López-Otín C, Blasco MA, Partridge L, Serrano M, Kroemer G. The hallmarks of aging. Cell. 2013;153(6): 1194-217. https://doi.org/10.1016/j.cell.2013.05.039.

2. Austad SN. Sex differences in health and aging: a dialog between the brain and gonad? Geroscience. 2019 Jun;41(3): 267-73. https://doi.org/10.1007/s11357-019-00081-3.

3. Dowling DK. Aging: manipulating sex differences. Curr Biol. 2014;24(20):R996-8. https://doi.org/10.1016/j. cub.2014.08.050.

4. Szentes N, Tékus V, Mohos V, Borbély É, Helyes Z. Exploratory and locomotor activity, learning and memory functions in somatostatin receptor subtype 4 gene-deficient mice in relation to aging and sex. Geroscience. 2019 Oct;41(5):631-41. https://doi.org/10.1007/s11357-01900059-1.

5. Nieman DC. Coronavirus disease-2019: a tocsin to our aging, unfit, corpulent, and immunodeficient society. J Sport Health Sci. 2020 Jul;9(4):293-301. https://doi. org/10.1016/j.jshs.2020.05.001.

6. Ambrosino I, Barbagelata E, Corbi G, Ciarambino T, Politi C, Moretti AM. Gender differences in treatment of coronavirus disease-2019. Monaldi Arch Chest Dis. 2020;90(4). https://doi.org/10.4081/monaldi.2020.1508.

7. Heim C, Nemeroff CB. The impact of early adverse experiences on brain systems involved in the pathophysiology of anxiety and affective disorders. Biol Psychiatry. 1999;46(11):1509-22. https://doi.org/10.1016/s0006-3223 (99)00224-3.

8. McEwen BS. Sex, stress and the hippocampus: allostasis, allostatic load and the aging process. Neurobiol Aging. 2002;23(5):921-39. https://doi.org/10.1016/s0197-4580(02 )00027-1. 
9. Miller DB, O'Callaghan JP. Aging, stress and the hippocampus. Ageing Res Rev. 2005;4(2):123-40. https://doi. org/10.1016/j.arr.2005.03.002.

10. Gray JD, Kogan JF, Marrocco J, McEwen BS. Genomic and epigenomic mechanisms of glucocorticoids in the brain. Nat Rev Endocrinol. 2017;13(11):661-73. https://doi. org/10.1038/nrendo.2017.97.

11. Lupien SJ, McEwen BS, Gunnar MR, Heim C. Effects of stress throughout the lifespan on the brain, behaviour and cognition. Nat Rev Neurosci. 2009;10(6):434-45. https://doi.org/10.1038/nrn2639.

12. McEwen BS, Akil H. Revisiting the stress concept: implications for affective disorders. J Neurosci. 2020;40(1):1221. https://doi.org/10.1523/JNEUROSCI.0733-19.2019.

13. Sapolsky RM, Krey LC, McEwen BS. The neuroendocrinology of stress and aging: the glucocorticoid cascade hypothesis. Endocr Rev. 1986;7(3):284-301. https://doi. org/10.1210/edrv-7-3-284.

14. De Rooij SR, Wouters H, Yonker JE, Painter RC, Roseboom TJ. Prenatal undernutrition and cognitive function in late adulthood. Proc Natl Acad Sci U S A. 2010;107(39):16881-6. https://doi.org/10.1073 /pnas.1009459107.

15. Maccari S, Polese D, Reynaert ML, Amici T, MorleyFletcher S, Fagioli F. Early-life experiences and the development of adult diseases with a focus on mental illness: the Human Birth Theory. Neuroscience. 2017;342:232-51. https://doi.org/10.1016/j.neuroscience.2016.05.042.

16. Vallée M, Maccari S, Dellu F, Simon H, Le Moal M, Mayo W. Long-term effects of prenatal stress and postnatal handling on age-related glucocorticoid secretion and cognitive performance: a longitudinal study in the rat. Eur J Neurosci. 1999;11(8):2906-16. https://doi.org/10.1046/j.14609568.1999.00705.

17. Yajima H, Haijima A, Khairinisa MA, Shimokawa N, Amano I, Takatsuru Y. Early-life stress induces cognitive disorder in middle-aged mice. Neurobiol Aging. 2018;64: $139-46$. https://doi.org/10.1016/j. neurobiolaging.2017.12.021.

18. Vanbesien-Mailliot CC, Wolowczuk I, Mairesse J, Viltart O, Delacre M, Khalife J, et al. Prenatal stress has proinflammatory consequences on the immune system in adult rats. Psychoneuroendocrinology. 2007;32(2):114-24. https://doi.org/10.1016/j.psyneuen.2006.11.005.

19. Lemaire V, Koehl M, Le Moal M, Abrous DN. Prenatal stress produces learning deficits associated with an inhibition of neurogenesis in the hippocampus. Proc Natl Acad Sci U S A. 2000 Sep 26;97(20):11032-7. https://doi. org/10.1073/pnas.97.20.11032.

20. Maccari S, Piazza PV, Kabbaj M, Barbazanges A, Simon H, Le Moal M. Adoption reverses the long-term impairment in glucocorticoid feedback induced by prenatal stress. J Neurosci. 1995;15(1 Pt 1):110-6. https://doi.org/10.1523 /JNEUROSCI.15-01-00110.1995.

21. Kadriu B, Musazzi L, Henter ID, Graves M, Popoli M, Zarate CA Jr. Glutamatergic neurotransmission: pathway to developing novel rapid-acting antidepressant treatments. Int J Neuropsychopharmacol. 2019;22((2)):119-35. https://doi.org/10.1093/ijnp/pyy094.

22. Popoli M, Yan Z, McEwen BS, Sanacora G. The stressed synapse: the impact of stress and glucocorticoids on glutamate transmission. Nat Rev Neurosci. 2011;13((1)): 22-37. Published 2011 Nov 30. https://doi.org/10.1038 /nrn3138.

23. Morrison JH, Baxter MG. The ageing cortical synapse: hallmarks and implications for cognitive decline. Nat Rev Neurosci. 2012;13(4):240-50. Published 2012 Mar 7. https://doi.org/10.1038/nrn3200.

24. Morrison JH, Hof PR. Life and death of neurons in the aging brain. Science. 1997;278(5337):412-9. https://doi. org/10.1126/science.278.5337.412.

25. Mairesse J, Gatta E, Reynaert ML, Marrocco J, MorleyFletcher S, Soichot M, et al. Activation of presynaptic oxytocin receptors enhances glutamate release in the ventral hippocampus of prenatally restraint stressed rats. Psychoneuroendocrinology. 2015;62:36-46. https://doi. org/10.1016/j.psyneuen.2015.07.005.

26. Marrocco J, Mairesse J, Ngomba RT, Silletti V, Van Camp $\mathrm{G}$, Bouwalerh H, et al. Anxiety-like behavior of prenatally stressed rats is associated with a selective reduction of glutamate release in the ventral hippocampus. J Neurosci. 2012;32(48):17143-54. https://doi.org/10.1523 /JNEUROSCI.1040-12.2012.

27. Morley-Fletcher S, Zuena AR, Mairesse J, Gatta E, Van Camp G, Bouwalerh H, et al. The reduction in glutamate release is predictive of cognitive and emotional alterations that are corrected by the positive modulator of AMPA receptors S 47445 in perinatal stressed rats. Neuropharmacology. 2018;135:284-96. https://doi. org/10.1016/j.neuropharm.2018.03.018.

28. Bale TL, Epperson CN. Sex differences and stress across the lifespan. Nat Neurosci. 2015;18(10):1413-20. https://doi. org/10.1038/nn.4112.

29. Reynaert ML, Marrocco J, Mairesse J, Lionetto L, Simmaco $\mathrm{M}$, Deruyter L, et al. Hedonic sensitivity to natural rewards is affected by prenatal stress in a sex-dependent manner. Addict Biol. 2016;21(6):1072-85. https://doi.org/10.1111 /adb.12270.

30. Van Camp G, Cigalotti J, Bouwalerh H, et al. Consequences of a double hit of stress during the perinatal period and midlife in female rats: mismatch or cumulative effect? Psychoneuroendocrinology. 2018a;93:45-55. https://doi. org/10.1016/j.psyneuen.2018.04.004.

31. Van Camp G, Cigalotti J, Bouwalerh H, Mairesse J, Gatta E, Palanza P, et al. Consequences of a double hit of stress during the perinatal period and midlife in female rats: mismatch or cumulative effect? Psychoneuroendocrinology. $2018 \mathrm{~b} ; 93: 45-55$. https://doi.org/10.1016/j. psyneuen.2018.04.004.

32. Zuena $\mathrm{AR}$, Mairesse $\mathrm{J}$, Casolini $\mathrm{P}$, Cinque $\mathrm{C}$, Alemà $\mathrm{GS}$, Morley-Fletcher S, et al. Prenatal restraint stress generates two distinct behavioral and neurochemical profiles in male and female rats. PLoS One. 2008;3(5):e2170. https://doi. org/10.1371/journal.pone.0002170.

33. Biala YN, Bogoch Y, Bejar C, Linial M, Weinstock M. Prenatal stress diminishes gender differences in behavior and in expression of hippocampal synaptic genes and proteins in rats. Hippocampus. 2011;21(10):1114-25. https://doi.org/10.1002/hipo.20825.

34. Kapoor A, Matthews SG. Short periods of prenatal stress affect growth, behaviour and hypothalamo-pituitary-adrenal axis activity in male guinea pig offspring. J Physiol. 
2005;566(Pt 3):967-77. https://doi.org/10.1113 /jphysiol.2005.090191.

35. Meisel RL, Dohanich GP, Ward IL. Effects of prenatal stress on avoidance acquisition, open-field performance and lordotic behavior in male rats. Physiol Behav. 1979;22(3):52730. https://doi.org/10.1016/0031-9384(79)90020-9.

36. Reznikov AG, Nosenko ND, Tarasenko LV. Prenatal stress and glucocorticoid effects on the developing gender-related brain. J Steroid Biochem Mol Biol. 1999;69(1-6):109-15. https://doi.org/10.1016/s0960-0760(98)00151-4.

37. Ward IL. Prenatal stress feminizes and demasculinizes the behavior of males. Science. 1972;175(4017):82-4. https://doi.org/10.1126/science.175.4017.82.

38. Becker G, Kowall M. Crucial role of the postnatal maternal environment in the expression of prenatal stress effects in the male rats. J Comp Physiol Psychol. 1977;91(6):1432-46. https://doi.org/10.1037/h0077401.

39. Dahlöf LG, Hård E, Larsson K. Influence of maternal stress on offspring sexual behaviour. Anim Behav. 1977;25(4): 958-68. https://doi.org/10.1016/0003-3472(77)90047-1.

40. Dörner G, Schenk B, Schmiedel B, Ahrens L. Stressful events in prenatal life of bi- and homosexual men. Exp Clin Endocrinol. 1983;81(1):83-7. https://doi.org/10.1055 /s-0029-1210210.

41. Morgan CP, Bale TL. Early prenatal stress epigenetically programs dysmasculinization in second-generation offspring via the paternal lineage. J Neurosci. 2011;31(33):11748-55. https://doi.org/10.1523/JNEUROSCI.1887-11.2011.

42. Morley-Fletcher S, Mairesse J, Van Camp G, Reynaert ML, Gatta E, Marrocco J, et al. Perinatal stress programs sex differences in the behavioral and molecular chronobiological profile of rats maintained under a 12-h light-dark cycle. Front Mol Neurosci. 2019;12:89. https://doi.org/10.3389 /fnmol.2019.00089.

43. Ward IL, Weisz J. Differential effects of maternal stress on circulating levels of corticosterone, progesterone, and testosterone in male and female rat fetuses and their mothers. Endocrinology. 1984;114(5):1635-44. https://doi. org/10.1210/endo-114-5-1635.

44. Nichols NR, Day JR, Laping NJ, Johnson SA, Finch CE. GFAP mRNA increases with age in rat and human brain. Neurobiol Aging. 1993;14(5):421-9. https://doi. org/10.1016/0197-4580(93)90100-p.

45. Day JR, Frank AT, O'Callaghan JP, Jones BC, Anderson JE. The effect of age and testosterone on the expression of glial fibrillary acidic protein in the rat cerebellum. Exp Neurol. 1998;151(2):343-6. https://doi.org/10.1006 /exnr.1998.6801.

46. Gatta E, Mairesse J, Deruyter L, Marrocco J, Van Camp G, Bouwalerh H, et al. Reduced maternal behavior caused by gestational stress is predictive of life span changes in risktaking behavior and gene expression due to altering of the stress/anti-stress balance. Neurotoxicology. 2018;66:13849. https://doi.org/10.1016/j.neuro.2018.04.005.

47. Pellow S, Chopin P, File SE, Briley M. Validation of open: closed arm entries in an elevated plus-maze as a measure of anxiety in the rat. J Neurosci Methods. 1985;14(3):149-67. https://doi.org/10.1016/0165-0270(85)90031-7.

48. Metz GA, Whishaw IQ. Cortical and subcortical lesions impair skilled walking in the ladder rung walking test: a new task to evaluate fore- and hindlimb stepping, placing, and co-ordination. J Neurosci Methods. 2002;115(2):169 79. https://doi.org/10.1016/s0165-0270(02)00012-2.

49. Dellu F, Mayo W, Cherkaoui J, Le Moal M, Simon H. A two-trial memory task with automated recording: study in young and aged rats. Brain Res. 1992 Aug 14;588(1):132-9. https://doi.org/10.1016/0006-8993(92)91352-f.

50. Anderson MJ. 2017. Permutational multivariate analysis of variance (PERMANOVA). Wiley StatsRef: Statistics Reference Online

51. Simpson ER, Mahendroo MS, Means GD, Kilgore MW, Hinshelwood MM, Graham-Lorence S, et al. Aromatase cytochrome P450, the enzyme responsible for estrogen biosynthesis. Endocr Rev. 1994;15(3):342-55. https://doi. org/10.1210/edrv-15-3-342.

52. Goyal D, Limesand SW, Goyal R. Epigenetic responses and the developmental origins of health and disease. J Endocrinol. 2019 Jul 1;242(1):T105-19. https://doi. org/10.1530/JOE-19-0009.

53. Hanson MA, Gluckman PD. Early developmental conditioning of later health and disease: physiology or pathophysiology? Physiol Rev. 2014 Oct;94(4):1027-76. https://doi. org/10.1152/physrev.00029.2013.

54. Lacagnina $\mathrm{S}$. The developmental origins of health and disease (DOHaD). Am J Lifestyle Med. 2019;14(1):47-50. https://doi.org/10.1177/1559827619879694.

55. Contreras-Vidal JL, Teulings HL, Stelmach GE. Elderly subjects are impaired in spatial coordination in fine motor control. Acta Psychol. 1998;100(1-2):25-35. https://doi. org/10.1016/s0001-6918(98)00023-7.

56. Diggles-Buckles V. Age-related slowing. In: Stelmach GE, Homberg V, editors. Sensorimotor impairment in the elderly. Norwell, MA: Kluwer Academic; 1993.

57. Seidler RD, Alberts JL, Stelmach GE. Changes in multi-joint performance with age. Mot Control. 2002;6(1):19-31. https://doi.org/10.1123/mcj.6.1.19.

58. Tang PF, Woollacott MH. Balance control in the elderly. In: Bronstein AM, Brandt T, Woollacott MH, editors. Clinical disorders of balance, posture and gait. London: Arnold; 1996.

59. Alagarsamy S, Marino MJ, Rouse ST, Gereau RW 4th, Heinemann SF, Conn PJ. Activation of NMDA receptors reverses desensitization of mGluR5 in native and recombinant systems. Nat Neurosci. 1999;2(3):234 40. https://doi. org/10.1038/6338.

60. Rosenbrock H, Kramer G, Hobson S, Koros E, Grundl M, Grauert M, et al. Functional interaction of metabotropic glutamate receptor 5 and NMDA-receptor by a metabotropic glutamate receptor 5 positive allosteric modulator. Eur J Pharmacol. 2010;639(1-3):40-6. https://doi.org/10.1016/j. ejphar.2010.02.057.

61. Buonaguro EF, Morley-Fletcher S, Avagliano C, Vellucci L, Iasevoli F, Bouwalerh $\mathrm{H}$, et al. Glutamatergic postsynaptic density in early life stress programming: topographic gene expression of mGlu5 receptors and Homer proteins. Prog Neuro-Psychopharmacol Biol Psychiatry. 2020;96:109725. https://doi.org/10.1016/j.pnpbp.2019.109725.

62. Linden AM, Shannon H, Baez M, Yu JL, Koester A, Schoepp DD. Anxiolytic-like activity of the mGLU2/3 receptor agonist LY354740 in the elevated plus maze test is disrupted in metabotropic glutamate receptor 2 and 3 knock- 
out mice. Psychopharmacology. 2005;179(1):284-91. https://doi.org/10.1007/s00213-004-2098.

63. Schoepp DD, Wright RA, Levine LR, Gaydos B, Potter WZ. LY354740, an mGlu2/3 receptor agonist as a novel approach to treat anxiety/stress. Stress. 2003;6(3):189-97. https://doi.org/10.1080/1025389031000146773.

64. Swanson CJ, Bures M, Johnson MP, Linden AM, Monn JA, Schoepp DD. Metabotropic glutamate receptors as novel targets for anxiety and stress disorders. Nat Rev Drug Discov. 2005;4(2):131-44. https://doi.org/10.1038/nrd1630.

65. Nicoletti F, Bockaert J, Collingridge GL, Conn PJ, Ferraguti F, Schoepp DD, et al. Metabotropic glutamate receptors: from the workbench to the bedside. Neuropharmacology. 2011;60(7-8):1017-41. https://doi.org/10.1016/j. neuropharm.2010.10.022.

66. Laloux C, Mairesse J, Van Camp G, Giovine A, Branchi I, Bouret S, et al. Anxiety-like behaviour and associated neurochemical and endocrinological alterations in male pups exposed to prenatal stress. Psychoneuroendocrinology. 2012;37(10):1646-58. https://doi.org/10.1016/j. psyneuen.2012.02.010.

67. Diering GH, Huganir RL. The AMPA receptor code of synaptic plasticity. Neuron. 2018;100(2):314-29. https://doi.org/10.1016/j.neuron.2018.10.018.

68. Paoletti P, Bellone C, Zhou Q. NMDA receptor subunit diversity: impact on receptor properties, synaptic plasticity and disease. Nat Rev Neurosci. 2013;14(6):383-400. https://doi.org/10.1038/nrn3504.

69. Derks NA, Krugers HJ, Hoogenraad CC, Joëls M, Sarabdjitsingh RA. Effects of early life stress on synaptic plasticity in the developing hippocampus of male and female rats. PLoS One. 2016;11((10)):e0164551. Published 2016 Oct 10. https://doi.org/10.1371/journal.pone.0164551.

70. Lesuis SL, Lucassen PJ, Krugers HJ. Early life stress impairs fear memory and synaptic plasticity; a potential role for GluN2B. Neuropharmacology. 2019;149:195-203. https://doi.org/10.1016/j.neuropharm.2019.01.010.

71. Lewerenz J, Hewett SJ, Huang Y, Lambros M, Gout PW, Kalivas PW, et al. The cystine/glutamate antiporter system $\mathrm{x}(\mathrm{c})(-)$ in health and disease: from molecular mechanisms to novel therapeutic opportunities. Antioxid Redox Signal. 2013;18(5):522-55. https://doi.org/10.1089/ars.2011.4391.

72. Nasca C, Bigio B, Zelli D, de Angelis P, Lau T, Okamoto M, et al. Role of the astroglial glutamate exchanger $\mathrm{xCT}$ in ventral hippocampus in resilience to stress. Neuron. 2017;96((2)):402-413.e5. https://doi.org/10.1016/j. neuron.2017.09.020.

73. Augustin I, Rosenmund C, Südhof TC, Brose N. Munc13-1 is essential for fusion competence of glutamatergic synaptic vesicles. Nature. 1999;400(6743):457-61. https://doi. org/10.1038/22768.

74. Südhof TC. The presynaptic active zone. Neuron. 2012;75(1):11-25. https://doi.org/10.1016/j. neuron.2012.06.012.

75. Marrocco J, Reynaert ML, Gatta E, Gabriel C, Mocaër E, Di Prisco S, et al. The effects of antidepressant treatment in prenatally stressed rats support the glutamatergic hypothesis of stress-related disorders. J Neurosci. 2014;34(6):2015-24. https://doi.org/10.1523/JNEUROSCI.4131-13.2014.

76. Solanas G, Peixoto FO, Perdiguero E, Jardí M, Ruiz-Bonilla V, Datta D, et al. Aged stem cells reprogram their daily rhythmic functions to adapt to stress. Cell. 2017;170((4)): 678-692.e20. https://doi.org/10.1016/j.cell.2017.07.035.

77. Mairesse J, Lesage J, Breton C, Bréant B, Hahn T, Darnaudéry $\mathrm{M}$, et al. Maternal stress alters endocrine function of the feto-placental unit in rats. Am J Physiol Endocrinol Metab. 2007;292(6):E1526-33. https://doi. org/10.1152/ajpendo.00574.2006.

78. Lesage J, Del-Favero F, Leonhardt M, Louvart H, Maccari $\mathrm{S}$, Vieau D, et al. Prenatal stress induces intrauterine growth restriction and programmes glucose intolerance and feeding behaviour disturbances in the aged rat. J Endocrinol. 2004 May;181(2):291-6. https://doi.org/10.1677/joe.0.1810291.

79. Vallée M, Mayo W, Maccari S, Le Moal M, Simon H. Longterm effects of prenatal stress and handling on metabolic parameters: relationship to corticosterone secretion response. Brain Res. 1996 Mar 18;712(2):287-92. https://doi.org/10.1016/0006-8993(95)01459-4.

80. Di S, Maxson MM, Franco A, Tasker JG. Glucocorticoids regulate glutamate and GABA synapse-specific retrograde transmission via divergent nongenomic signaling pathways. J Neurosci. 2009;29(2):393-401. https://doi.org/10.1523 /JNEUROSCI.4546-08.2009.

81. Karst H, Berger S, Turiault M, Tronche F, Schütz G, Joëls M. Mineralocorticoid receptors are indispensable for nongenomic modulation of hippocampal glutamate transmission by corticosterone. Proc Natl Acad Sci U S A. 2005;102(52):19204-7. https://doi.org/10.1073 /pnas.0507572102.

82. Nasca C, Bigio B, Zelli D, Nicoletti F, McEwen BS. Mind the gap: glucocorticoids modulate hippocampal glutamate tone underlying individual differences in stress susceptibility. Mol Psychiatry. 2015;20(6):755-63. https://doi. org/10.1038/mp.2014.96.

83. Grundwald NJ, Brunton PJ. Prenatal stress programs neuroendocrine stress responses and affective behaviors in second generation rats in a sex-dependent manner. Psychoneuroendocrinology. 2015 Dec;62:204-16. https://doi.org/10.1016/j.psyneuen.2015.08.010.

84. Welberg L, Thrivikraman KV, Plotsky PM. Combined preand postnatal environmental enrichment programs the HPA axis differentially in male and female rats. Psychoneuroendocrinology. 2006 Jun;31(5):553-64. https://doi.org/10.1016/j.psyneuen.2005.

85. Bartz JA, Zaki J, Bolger N, Ochsner KN. Social effects of oxytocin in humans: context and person matter. Trends Cogn Sci. 2011;15(7):301-9. https://doi.org/10.1016/j. tics.2011.05.002.

86. Bartz JA, Zaki J, Ochsner KN, Bolger N, Kolevzon A, Ludwig N, et al. Effects of oxytocin on recollections of maternal care and closeness. Proc Natl Acad Sci U S A. 2010;14(107(50)):21371-5. https://doi.org/10.1073 /pnas.1012669107.

87. Champagne F, Diorio J, Sharma S, Meaney MJ. Naturally occurring variations in maternal behavior in the rat are associated with differences in estrogen-inducible central oxytocin receptors. Proc Natl Acad Sci U S A. 2001;98(22):12736-41. https://doi.org/10.1073 /pnas.221224598.

88. Lakshminarasimhan H, Chattarji S. Stress leads to contrasting effects on the levels of brain derived neurotrophic factor 
in the hippocampus and amygdala. PLoS One. 2012;7(1): e30481. https://doi.org/10.1371/journal.pone.0030481.

89. Shi SS, Shao SH, Yuan BP, Pan F, Li ZL. Acute stress and chronic stress change brain-derived neurotrophic factor (BDNF) and tyrosine kinase-coupled receptor (TrkB) expression in both young and aged rat hippocampus. Yonsei Med J. 2010;51(5):661-71. https://doi.org/10.3349 /ymj.2010.51.5.661.

90. Magariños AM, Li CJ, Gal Toth J, Bath KG, Jing D, Lee FS, et al. Effect of brain-derived neurotrophic factor haploinsufficiency on stress-induced remodeling of hippocampal neurons. Hippocampus. 2011;21(3):253-64. https://doi.org/10.1002/hipo.20744.

91. Pawluski JL, Valença A, Santos AI, Costa-Nunes JP, Steinbusch HW, Strekalova T. Pregnancy or stress decrease complexity of CA3 pyramidal neurons in the hippocampus of adult female rats. Neuroscience. 2012;227:201-10. https://doi.org/10.1016/j.neuroscience.2012.09.059.

92. Suri D, Veenit V, Sarkar A, Thiagarajan D, Kumar A, Nestler EJ, et al. Early stress evokes age-dependent biphasic changes in hippocampal neurogenesis, BDNF expression, and cognition. Biol Psychiatry. 2013;73(7):658-66. https://doi.org/10.1016/j.biopsych.2012.10.023.
93. Middeldorp J, Hol EM. GFAP in health and disease. Prog Neurobiol. 2011;93(3):421-43. https://doi.org/10.1016/j. pneurobio.2011.01.005.

94. Norton WT, Aquino DA, Hozumi I, Chiu FC, Brosnan CF. Quantitative aspects of reactive gliosis: a review. Neurochem Res. 1992;17(9):877-85. https://doi. org/10.1007/BF00993263.

95. McEwen BS, Nasca C, Gray JD. Stress effects on neuronal structure: hippocampus, amygdala, and prefrontal cortex. Neuropsychopharmacology. 2016;41(1):3-23. https://doi. org/10.1038/npp.2015.171.

96. Foster KD, Conn CA, Kluger MJ. Fever, tumor necrosis factor, and interleukin-6 in young, mature, and aged Fischer 344 rats. Am J Phys. 1992;262(2 Pt 2):R211-5. https://doi. org/10.1152/ajpregu.1992.262.2.R211.

97. Fagiolo U, Cossarizza A, Scala E, Fanales-Belasio E, Ortolani C, Cozzi E, et al. Increased cytokine production in mononuclear cells of healthy elderly people. Eur J Immunol. 1993;23(9):2375-8. https://doi.org/10.1002 /eji.1830230950.

Publisher's note Springer Nature remains neutral with regard to jurisdictional claims in published maps and institutional affiliations. 